\title{
Fiscal Stimulus with Learning-By-Doing
}

\author{
Antonello d'Alessandro, Giulio Fella and Leonardo Melosi*
}

May 2018

\begin{abstract}
Using a Bayesian SVAR analysis, we document that an increase in government purchases raises private consumption, the real wage and total factor productivity (TFP) while reducing inflation. Each of these facts is hard to reconcile with both neoclassical and New-Keynesian models. We extend a standard New-Keynesian model to allow for skill accumulation through past work experience, following Chang, Gomes and Schorfheide (2002). An increase in government spending increases hours and induces skill accumulation and higher measured TFP and real wages in subsequent periods. Future marginal costs fall lowering future expected inflation and, through the monetary policy rule, the real interest rate. Consumption increases as a result.
\end{abstract}

Keywords: Fiscal policy transmission, consumption, real wage.

JEL Classification: E62, E63.

*Antonello d'Alessandro: Bank of Italy, antonello.dalessandro@bancaditalia.it. Giulio Fella: Queen Mary University of London, CFM, and IFS, g.fella@qmul.ac.uk. Leonardo Melosi: Federal Reserve Bank of Chicago, lmelosi@frbchi.org. The views expressed in the paper are those of the authors and do not necessarily reflect those of the institutions they are affiliated with. 


\section{Introduction}

What are the effects of changes in government spending on aggregate output? What is the mechanism by which they propagate? Though the limitations of monetary policy in the face of the financial crisis of 2008 have sparked a renewed interest in the role of government spending, there is a general lack of consensus on the answer. This paper provides an empirical and theoretical analysis of the effects of government spending shocks on consumption, TFP, the real wage and inflation. Our empirical analysis estimates a Bayesian SVAR model on U.S. time-series for the period 1954-2007 and identifies government spending shocks using two distinct approaches, following respectively Blanchard and Perotti (2002) and Auerbach and Gorodnichenko's (2012) implementation of Ramey (2011). In line with previous empirical studies using similar methodologies and identification strategies, we find that a positive government spending shock increases consumption, TFP and the real wage and reduces inflation. ${ }^{1}$

With few exceptions discussed below, the observed responses of private consumption and the real wage to innovations in government spending are hard to reconcile with the predictions of existing models with intertemporally-optimizing consumers. these models, the higher present value of taxes to finance the increase in government spending generates a negative wealth effect that induces a fall in consumption and leisure and a decline the real wage. This mechanism, which is at the heart of the real business cycle model (Baxter and King, 1993), is powerful enough for the result to extend to New Keynesian models with optimizing consumers. Furthermore, most theoretical models imply that inflation increases, rather than falls, in response to a fiscal expansion.

This paper proposes a novel explanation that can account for the estimated joint response of consumption, TFP, real wages and inflation to a government spending shock. The key channel is the interaction of skill accumulation through past work experiencethe "learning-by-doing" (LBD) mechanism, originally proposed by Chang et al. (2002) in an RBC framework - with wage and price rigidities. A positive shock to government

\footnotetext{
${ }^{1}$ Section 2 discusses the existing empirical literature.
} 
spending increases hours and, through the LBD mechanism, induces skill accumulation and higher measured TFP and real wages in subsequent periods. For a large set of values of the degrees of wage and price stickyness, the increase in future productivity lowers future marginal costs and therefore the expected rate of inflation. Through the monetary policy rule, the fall in expected inflation results in a persistent reduction in the policy rate and the short-term real interest rate. The associated decline in the current long-term real interest rate increases consumption.

It is worth noting that the presence of nominal rigidities is crucial to generate the comovement of consumption and hours in response to a shock to government spending. The wedge (equal to the sum of the price and wage mark ups) between the consumption/leisure marginal rate of substitution and the marginal product of labor is constant in the absence of nominal rigidities. Since an increase in hours worked reduces the marginal product of labor but increases the marginal rate of substitution, equilibrium requires consumption to fall in the absence of nominal rigidities. ${ }^{2}$ Vice versa, the combination of LBD and nominal rigidities implies that an increase in hours is accompanied by a fall in the wedge which can be large enough to break the negative association between consumption and hours worked.

Though it crucially relies on nominal rigidities, our mechanism is very different from what Dupor and Li (2015) call the "expected-inflation channel" which is common to all New-Keynesian models. According to this mechanism, an increase in government spending results in higher expected inflation and a lower real interest, and therefore higher consumption, if the central bank is non-responsive to inflation; i.e., if it raises the policy rate by less than the increase in expected inflation (Eggertsson, 2011; Christiano et al., 2011; Woodford, 2011). Instead the transmission channel in our model works through a fall in expected inflation to which the central bank responds by reducing the policy rate and, by the Taylor principle, the real rate. In our framework, the consumption

\footnotetext{
${ }^{2}$ Bilbiie (2009) shows that, given a constant wedge, a positive co-movement between consumption and hours in response to a government spending shock requires either consumption or leisure to be inferior goods.
} 
and output response is larger the more, rather than less, responsive the central bank is to inflation. This prediction is in line with the findings of Dupor and Li (2015) in the context of a structural VAR that: (i) inflation responds negatively to innovations in government spending; (ii) the response of inflation is more negative, and that of consumption positive and larger, in periods in which the central bank responds more aggressively to inflation. Our mechanism is also consistent with the empirical evidence in Hall and Thapar (2018) and Jørgensen and Ravn (2018) and discussed in Section 2.2.

Our contribution is related to a relative small number of papers that also identify mechanisms that can generate a positive response of consumption to government spending shocks. Devereux et al. (1996) find that government spending endogenously increases TFP, and possibly consumption and the real wage, in a real business cycle model with increasing return to specialization. Ravn et al. (2006) show that a real business cycle model in which consumers form consumption habits on a good-by-good basis (deep-habit) implies a positive response of consumption and the real wage by generating a fall in price mark-ups. Ercolani and Pavoni (2016) show that government expenditure on health care reduces precautionary saving and increases consumption by providing insurance against health expenditure shocks. A number of papers obtain a positive consumption response within a New-Keynesian framework. Galí et al. (2007) find that a government expenditure shock increases aggregate consumption in an economy with a sufficiently large share of hand-to-mouth (non-optimizing) consumers and a sufficiently pro-cyclical, noncompetitive, real wage. Corsetti et al. (2012) show that consumption responds positively to a government expenditure shock if the latter is partly financed by future spending reductions. Monacelli and Perotti (2008) find that, if preferences display a sufficiently small wealth effect on labor supply, consumption and leisure are complements and price rigidity implies a positive response of the real wage and consumption to a government expenditure shock. Gnocchi et al. (2016) show how allowing for home production implies a positive consumption response to government spending by generating complementarity between consumption and leisure without imposing a low wealth effect. Christiano et al. 
(2011) find that consumption responds positively to a government spending shock when the zero lower bound constraint on the nominal interest rate is binding. Finally, Rendahl (2016) shows that, at the zero lower bound, an increase in government spending increases consumption, but reduces the real wage, in an economy with a frictional labor market and rigid nominal wages.

With the exception of Devereux et al. (1996), though, all the above papers, imply that the increase in hours induced by an increase in non-productive government spending does not affect TFP and reduces aggregate labor productivity. ${ }^{3}$ Instead our framework predicts that, to the extent that growth accounting does not account for workers' skills, the increase in labor productivity is reflected in an increase in measured TFP. This is consistent with the empirical evidence documenting a positive response of aggregate labor productivity (Ramey, 2011) and TFP (Bachmann and Sims, 2012; Jørgensen and Ravn, 2018) to a government spending shock.

Finally, after submitting this paper we have become aware of two very related works. Engler and Tervala (2016) also study the implications of the same learning-by-doing mechanism studied here in the presence of nominal rigidities. Under the assumptions that changes in employment affect the level of productivity permanently and that the monetary authority targets only inflation, they find that the introduction of learningby-doing raises the present value fiscal multiplier by a factor of 6 . Jørgensen and Ravn (2018) document the same set of stylized facts as in the present paper and show that they can be accounted for by a model with variable technology utilization, along the lines of Bianchi et al. (2017).

The remainder of this paper is organized as follow. Section 2 presents our estimates for the effects of government spending shocks. Section 3 introduces the model and discusses its parameterization. Section 4 illustrates the main mechanism simulating a parsimonious version of the model. Section 5 reports results for the full-fledged model. Section 6

\footnotetext{
${ }^{3}$ Inherently-productive government expenditure, though, always increases total factor productivity and, possibly, consumption and the real wage (Baxter and King, 1993; Glomm and Ravikumar, 1997; Linnemann and Schabert, 2006).
} 
concludes.

\section{Time-series evidence}

In this section, we present time-series evidence on the effects of government spending shocks using a structural vector autoregression approach. We conduct our empirical analysis using U.S. data, for comparability with most of existing studies. We show below that our findings that a positive government spending shock increases consumption, TFP and the real wage, while reducing inflation, are robust across the identification schemes of Blanchard and Perotti (2002) and Auerbach and Gorodnichenko (2012). We also compare our findings to those of previous empirical studies.

We estimate a Bayesian VAR with four lags and a constant using nine variables: the TFP measure constructed by Fernald (2012), real per-capita government spending (the sum of government consumption and investment), non-durable consumption, investment, GDP and government receipts ${ }^{4}$, the real wage, hours, the nominal interest rate and inflation. All variables, except the nominal interest rate and inflation, are in logs. The appendix describes the data in detail. Following Sims and Zha (1998), we adopt a unitroot prior for the parameters of this empirical model with a pre-sample of four quarters. As in Giannone et al. (2015), the five prior hyperparameters are chosen so as to maximize the marginal likelihood. ${ }^{5}$ Data are quarterly and range from 1954:3 to 2007:4. ${ }^{6}$

\footnotetext{
${ }^{4}$ For the TFP series, we employ the real-time, quarterly series on TFP for the U.S. business sector, adjusted for variations in factor utilization (labor effort and capital's workweek), constructed by Fernald (2012). As in Auerbach and Gorodnichenko (2012), government spending is defined as the sum of direct consumption and investment purchases excluding the imputed rent on government capital stock. Government receipts include direct and indirect taxes net of transfers to businesses and individuals.

${ }^{5}$ The five hyperparameters affect each of the following: (i) the prior tightness for the autoregressive coefficients of order one; (ii) the prior variance for the autoregressive coefficients of lags higher than one; (iii) the weight for the priors for the variance and covariance matrix of innovations. (iv) the weight on copersistence prior dummy observations. It reflects the belief that when the data are stable at their initial levels, it will tend to persist at that level. ( $\mathrm{v}$ ) Weight on own-persistence prior dummy observations. It reflects the belief that when a variable has been stable at its initial level, it will tend to persist at that level, regardless of the value of other variables. The prior relies on the first and the second moment of the observable, which are computed using a pre-sample of four quarters. The prior is implemented via dummy observations.
}

${ }^{6}$ The start date of the sample period is dictated by data availability, specifically for the nominal 


\section{$2.1 \quad$ Identification}

We denote by $X_{t}=\left[A_{t}, Z_{t}\right]$ the vector of variables in the baseline VAR, where $A_{t}$ denotes the log of TFP and $Z_{t}$ the vector of the remaining variables with government expenditure ordered first.

We identify government spending shocks as innovations to government spending that are: (a) contemporaneously orthogonal to TFP movements; (b) pre-determined with respect to all other variables in $Z_{t}$.

Assumption (a) addresses the findings in Ben Zeev and Pappa (2015b) that the positive response of TFP (and output) to unanticipated (defense) spending shocks in U.S. quarterly data may be due to correlated measurement error in the two variables. They argue that orthogonalization controls for the measurement error component from expenditure shock.

As far as assumption (b) is concerned, following Blanchard and Perotti (2002), we assume that government spending is not affected within the quarter by innovations to the other variables included in the VAR. The assumption-which relies on implementation lags of discretionary changes in government spending - implies that the reduced-form residuals from the equation for government spending in the VAR are structural innovations to government spending.

However, as highlighted in Ramey (2011), the timing of fiscal shocks is crucial for the identification of their effects. The approach in Blanchard and Perotti (2002) may fail to identify innovations to government spending to the extent that changes in government spending are anticipated. In the spirit of Ramey (2011), we employ a second identification strategy that controls for these anticipation effects by augmenting the baseline VAR with a variable capturing expectations about government spending.

Specifically, we rely on the data and method proposed in Auerbach and Gorodnichenko (2012), who construct a continuous forecast series for government spending growth ${ }^{7}$ by interest rate. The end date was chosen to exclude the 2008 financial crisis.

${ }^{7}$ Because there have been numerous data revisions in the National Income and Product Accounts since the dates of these forecasts, forecast growth rates rather than levels are used. 
splicing the Survey of Professional Forecasters (SPF) and the (Greenbook) forecast prepared by the FRB staff for FOMC meetings. We augment the vector of variables $Z_{t}$ in the baseline VAR with the forecast error $F E_{t}^{G}$ computed as the difference between the government spending growth forecast series and the actual, first-release, series of the spending growth rate. Thus, the variables in the model are $\hat{X}_{t}=\left[A_{t}, F E_{t}^{G}, Z_{t}\right]$ and an innovation in the forecast error $F E_{t}^{G}$ is interpreted as an unanticipated shock. ${ }^{8}$

\subsection{Results}

Figure 1 plots the estimated impulse response under Blanchard and Perotti's (2002) approach. In this and all the following figures time on the horizontal axis is measured in quarters from the shock, the (annualized) nominal interest rate and inflation are measured as percentage-point deviations from the pre-shock level, while all other variables are expressed in percentage deviation from their pre-shock level. The figures show the response of the observables to a fiscal shock that raises spending by $1 \%$ of trend GDP upon impact. Thus, the initial response of GDP may be interpreted as multiplier. For each variable, we report the median as well as the 15th and 85th percentiles of the posterior distribution of impulse responses.

Government spending increases significantly and persistently. The response of GDP is around 1 on impact. It displays a persistent, hump-shaped increase in subsequent quarters. Private consumption also shows a sizable and persistent increase, peaking at about 0.5 per cent above its pre-shock level around 10 quarters after the shock. TFP and the real wage also display a positive and persistent response. Finally, the response of inflation is negative up to around 13 quarters after the shock while the nominal interest rate also falls up to 20 quarters out.

Our findings are in line with previous empirical studies using a structural VAR methodology and similar identification strategies. Blanchard and Perotti (2002), Fatás

\footnotetext{
${ }^{8}$ The studies by Hall and Thapar (2018) and Jørgensen and Ravn (2018), discussed below, also use a similar identification strategy.
} 
and Mihov (2001), Perotti (2008), Galí et al. (2007), Ravn et al. (2012), Ben Zeev and Pappa (2015a), Hall and Thapar (2018) and Jørgensen and Ravn (2018) document that consumption responds positively to government spending shocks, while Rotemberg and Woodford (1992), Galí et al. (2007), Perotti (2008), Pappa (2009), Hall and Thapar (2018) and Jørgensen and Ravn (2018) report similar results for the real wage. Within this literature, the main exception is Mountford and Uhlig (2009) who find a small and short-lived response of consumption and the real wage. Studies using an alternative, narrative, identification approach — such as Ramey and Shapiro (1998), Edelberg et al. (1999), Burnside et al. (2004) and Ramey (2011) - typically find that consumption and the real wage fall during episodes of large, exogenous increases in defense spending. ${ }^{9}$ Caldara and Kamps (2008) argue that, controlling for differences in the specification of reduced-form models, private consumption significantly increases after a government spending shock, regardless of the identification approach employed.

As far as productivity is concerned, our findings are consistent with the empirical evidence in Bachmann and Sims (2012), Ramey (2011) and Jørgensen and Ravn (2018) documenting a positive response of aggregate productivity to a government spending shock. ${ }^{10}$ Contrary to Ben Zeev and Pappa's (2015b) findings for defense spending shocks, in our case the response of TFP, output and consumption to general government spending shocks remains positive despite imposing that the shocks are orthogonal to TFP within the quarter.

Quite interestingly, inflation falls in response to the fiscal shock. This result is very striking because most theoretical models imply that inflation increases in response to a fiscal expansion. This result is robust across the two identification schemes we use and consistent with those in Edelberg et al. (1999), Fatás and Mihov (2001), Canova and

\footnotetext{
${ }^{9}$ Compared to the VAR methodology with the standard Blanchard and Perotti (2002) identification, the narrative approach offers a convincing instrument to deal with the possibility that changes in government spending are anticipated. Yet, it has its own limitations. First, it can only study the effects of a very specific class of shocks; namely shocks to defense spending. Secondly, it may capture the effect of concomitant fiscal shocks of opposite sign. Finally, the transmission mechanism of government spending may be impaired in times of war; e.g. by rationing, as was arguably the case during WWII (Hall, 2009).

${ }^{10}$ Nekarda and Ramey (2011) document that while the aggregate TFP response is positive, the partial equilibrium short-run response at the (4-digit manufacturing) industry level is slightly negative.
} 
Pappa (2007), Mountford and Uhlig (2009), Dupor and Li (2015), Jørgensen and Ravn (2018) and Hall and Thapar (2018).

Figure 2 reports the responses for the same series for the alternative approach in Auerbach and Gorodnichenko (2012). Note that since the Greenbook/SPF forecast series starts in 1966:Q4, the associated VAR is estimated over the period 1966:4 to 2007:4. Overall the results are qualitatively similar to those reported in Figure 1. In particular, the responses of consumption and inflation are, respectively, positive and negative, and statistically significant.

We have also run a number of robustness checks; namely: (a) we have replaced the GDP deflator, our baseline measure of inflation, with the CPI; (b) we have replaced the series of TFP with the average labor productivity; (c) we have included commodity prices. In the interest of space, we report our results in the Online Appendix. In line with a similar exercise conducted by Jørgensen and Ravn (2018) with a frequentist approach, we find that inflation persistently falls in all cases. We also find that, qualitatively, the response of consumption, the real wage, and TFP is consistent with the findings in this section.

\section{The model}

In this section we present a New-Keynesian DSGE model along the lines of Smets and Wouters (2007) augmented with the LBD mechanism proposed by Chang et al. (2002).

\subsection{Model structure}

Intermediate goods firms are monopolistic competitors that produce intermediate goods using labor and capital inputs. The level of workers' skills depend on hours worked in the previous period. Final goods producers aggregate intermediate goods to produce a homogeneous good that can be used for private and public consumption and investment. Households consume and provide labor and capital services. Nominal frictions imply 
prices and wages adjust only infrequently. Financial markets are complete.

\subsubsection{Final good firms}

The final good is a bundle of the $j \in[0,1]$ intermediate goods, produced using the aggregation technology

$$
Y_{t}=\left[\int_{0}^{1} Y_{t}(j)^{\frac{1}{1+\lambda_{f}}} d j\right]^{1+\lambda_{f}}
$$

where $Y_{t}$ denotes the quantity of the final good at time $t$ and $Y_{t}(j)$ the quantity of intermediate good $j$.

The final good can be used for private, $C_{t}$, and government, $G_{t}$, consumption as well as fixed investment $F_{t}$. Final good firms are price takers on both their output and input markets. Their optimality condition yields the following demand function for intermediate goods

$$
Y_{t}(j)=\left(\frac{P_{t}(j)}{P_{t}}\right)^{-\frac{1+\lambda_{f}}{\lambda_{f}}} Y_{t},
$$

where $P_{t}$ denotes the price of the final good and $P_{t}(j)$ is the price of intermediate good $j$. Given constant returns, the zero profit condition together with equation (2) implies that $P_{t}=\left[\int_{0}^{1} P_{t}(j)^{-\frac{1}{\lambda_{f}}} d j\right]^{-\lambda_{f}}$.

\subsubsection{Intermediate good firms}

Producers of the differentiated intermediate goods are monopolistic competitors facing the demand schedule (2). Their production function is given by

$$
Y(j)=K_{t}(j)^{\alpha}\left(H_{t}(j) X_{t}\right)^{1-\alpha}
$$

where $K_{t}(j)$ and $H_{t}(j)$ are, respectively, the quantities of capital and worker-hours used by firm $j$. 
The productivity of worker-hours increases in the skill level of the average worker $X_{t}$, which depends on past labor supplies and is given to the individual firm. Following Chang et al. (2002), the skill level $X_{t}$ of the average worker is assumed to depend on hours worked in the past. In particular, assuming symmetric equilibrium, its law of motion is given by

$$
X_{t}=X_{t-1}^{\rho_{x}} H_{t-1}^{\mu_{n}} \quad 0 \leq \rho_{x}<1, \mu_{n} \geq 0
$$

where $\rho_{x}$ captures the persistence of the past stock of skills and $\mu_{n}$ the impact elasticity to hours in the previous period.

The markets for capital and labor are competitive. Hence, cost minimization implies a common capital-labor ratio

$$
\frac{K_{t}}{H_{t}}=\frac{\alpha}{1-\alpha} \frac{W_{t}}{R_{t}}
$$

where $W_{t}$ and $R_{t}$ denote, respectively, the nominal wage and rental cost of capital. As a result, the nominal marginal cost is also common and given by

$$
M C_{t}=\frac{R_{t}^{\alpha} W_{t}^{1-\alpha}}{\alpha^{\alpha}(1-\alpha)^{(1-\alpha)} X_{t}^{(1-\alpha)}} .
$$

Following Calvo (1983) we assume that in every period a fraction $\zeta_{p}$ of firms cannot re-optimize their price $P_{t}(j)$. The fraction $\left(1-\zeta_{p}\right)$ of firms able to re-optimize set their price to solve

$$
\max _{P_{t}(j)^{\text {new }}} \mathbb{E}_{t}\left[\sum_{s=0}^{\infty}\left(\zeta_{p} \beta\right)^{s} \Xi_{t+s}\left(P_{t}(j)^{\text {new }}-M C_{t+s}\right) Y_{t+s}(j)\right]
$$

subject to the demand function (2). The term $\beta^{s} \Xi_{t+s}$ is the stochastic discount factor expressing the current value of one unit of money at time $t+s$ in terms of consumption at time $t$.

In symmetric equilibrium, the law of motion for the aggregate price level is 


$$
P_{t}=\left[\left(1-\zeta_{p}\right)\left(P_{t}^{\text {new }}\right)^{-\frac{1}{\lambda_{f}}}+\zeta_{p} P_{t-1}^{-\frac{1}{\lambda_{f}}}\right]^{\lambda_{f}}
$$

\subsubsection{Households}

Households are differentiated and indexed by $l \in[0,1]$. They supply labor hours $H_{t}(l)$ to perfectly competitive labor contractors that bundle them into aggregate labor services according to the function

$$
H_{t}=\left[\int_{0}^{1} H_{t}(l)^{\frac{1}{1+\lambda w}} d l\right]^{1+\lambda_{w}}
$$

Profit maximization by labor contractors yields the demand for the $l$ labor type

$$
H_{t}(l)=\left(\frac{W_{t}(l)}{W_{t}}\right)^{-\frac{1+\lambda w}{\lambda w}} H_{t}
$$

where $W_{t}(l)$ is the unit cost of labor services of type $l$ and $W_{t}=\left[\int_{0}^{1} W_{t}(l)^{-\frac{1}{\lambda_{w}}} d l\right]^{-\lambda_{w}}$ is the aggregate wage index.

Letting $C_{t}(l)$ denote consumption of household $l$, its objective function is given by

$$
\mathbb{E}_{t} \sum_{s=0}^{\infty} \beta^{s}\left\{\log \left(C_{t+s}(l)-\gamma C_{t+s-1}(l)\right)-\frac{H_{t+s}^{1+\varphi}(l)}{1+\varphi}\right\}
$$

where $\gamma$ measures household's habit persistence in consumption and $\varphi$ is the inverse of the labor supply elasticity.

Households maximize lifetime utility in equation (11) subject to the dynamic budget constraint

$$
\begin{gathered}
P_{t} C_{t}(l)+P_{t} F_{t}(l)+B_{t}(l)+\mathbb{E}_{t}\left[\Xi_{t+1} A_{t+1}(l)\right] \leq i_{t-1} B_{t-1}(l)+A_{t} \\
+W_{t}(l) H_{t}(l)+\Pi_{t}+\left[R_{t} u_{t}(l)-P_{t} a\left(u_{t}(l)\right)\right] \bar{K}_{t-1}(l)-P_{t} T_{t}
\end{gathered}
$$

The right-hand side of the expression (12) corresponds to the household's income net of the lump-sum taxes (or transfers) $T_{t}$. Total income is the sum of different components: 
interest income from zero-coupon government bonds $i_{t-1} B_{t-1}(l)$, the state-contingent payoff $A_{t}$ from Arrow securities, labor income $W_{t}(l) H_{t}(l)$, nominal dividends $\Pi_{t}$ from the imperfectly competitive intermediate firms and net income $\left[R_{t} u_{t}(l)-P_{t} a\left(u_{t}(l)\right)\right] \bar{K}_{t-1}(l)$ from renting physical capital to intermediate firms. Following Smets and Wouters (2003) the effective capital rented to intermediate goods producer firms is $K_{t}(l)=u_{t}(l) \bar{K}_{t-1}(l)$, where $u_{t}(l)$ is the utilization rate of installed capital chosen by households. Households receive $R_{t}$ for each effective unit of capital service supplied. However, they must pay a cost of utilization $a\left(u_{t}(l)\right)$, expressed in term of the consumption good. As Christiano et al. (2005) we assume $a(\cdot)$ is quadratic with $a(1)=0, a^{\prime \prime}(1)>0$, and $u_{t}=1$ in the symmetric, steady state equilibrium. Income can be used for consumption $C_{t}(l)$ and saving in either physical capital $F_{t}(l)$, government bonds $B_{t}(l)$ or a portfolio of Arrow securities with random payoff $A_{t+1}$ priced with pricing kernel $\Xi_{t+1}$.

As in Christiano et al. (2005) capital accumulation evolves according to:

$$
\bar{K}_{t}(l)=(1-\delta) \bar{K}_{t-1}(l)+\left[1-S\left(\frac{F_{t}(l)}{F_{t-1}(l)}\right)\right] F_{t}(l)
$$

where $\delta$ is the depreciation rate, and $S(\cdot)$ is the quadratic cost of adjusting investment with $S(1)=S^{\prime}(1)=0$ and $S^{\prime \prime}(\cdot)>0$.

Households face Calvo-style wage setting frictions. In each period a fraction $\zeta_{w}$ of them are unable to re-optimize their wage and set it according to the pre-determined rule

$$
W_{t}(l)=\left(\pi_{t-1}\right)^{\iota_{w}}(\pi)^{1-\iota_{w}} W_{t-1}(l)
$$

The fraction $\left(1-\zeta_{w}\right)$ of households able to re-optimize choose their wage to solve

$$
\max _{W_{t}^{\text {new }}} \mathbb{E}_{t} \sum_{s=0}^{\infty} \zeta_{w}^{s} \beta^{s}\left\{-\frac{\left(H_{t+s}(l)\right)^{1+\varphi}}{1+\varphi}\right\}
$$


subject to (12), (10) and

$$
W_{t+s}(l)=\prod_{l=1}^{s}(\pi)^{\left(1-i_{w}\right)}\left(\pi_{t+l-1}\right)^{i_{w}} W_{t}^{\text {new }}(l)
$$

It follows that in symmetric equilibrium, the law of motion of the aggregate wage satisfies

$$
W_{t}=\left\{\left(1-\zeta_{w}\right)\left(W_{t}^{n e w}\right)^{-\frac{1}{\lambda w}}+\zeta_{w}\left[(\pi)^{\left(1-i_{w}\right)}\left(\pi_{t-1}\right)^{i_{w}} W_{t-1}\right]^{-\frac{1}{\lambda_{w}}}\right\}^{-\lambda_{w}}
$$

\subsubsection{Government policies}

Let $G D P_{t}$ denote the total real flow of consumable resources

$$
G D P_{t}=C_{t}+F_{t}+G_{t}
$$

as in Christiano et al. (2010), with $g d p_{t}$ being its logarithm.

The central bank sets the nominal interest rate $i_{t}$ according to the linearized Taylor rule

$$
i_{t}-i=\rho_{r}\left(i_{t-1}-i\right)+\left(1-\rho_{r}\right)\left[\phi_{p}\left(\mathbb{E}_{t} \pi_{t+1}-\pi\right)+\frac{\phi_{\Delta y}}{4}\left(g d p_{t}-g d p_{t-1}\right)\right]
$$

in Christiano et al. (2014), where $\rho_{r}$ is the interest rate smoothing parameter. Here $i_{t}-i$ and $\mathbb{E}_{t} \pi_{t+1}-\pi$ are the deviations of, respectively, the nominal interest rate and anticipated inflation from their (deterministic) steady state levels and $\left(g d p_{t}-g d p_{t-1}\right)$ the deviation of GDP growth from its (zero) steady state value.

Government spending is assumed to evolve according to

$$
\log G_{t}=\left(1-\rho_{g}\right) \log G+\rho_{g} \log G_{t-1}+\varepsilon_{t}^{g},
$$

where $\varepsilon_{t}^{g} \stackrel{\text { iid }}{\sim}(0,1)$, and is financed either by issuing bonds or by lump-sum taxation. 
Therefore, the government dynamic budget identity is

$$
P_{t} G_{t}+i_{t-1} B_{t-1}=P_{t} T_{t}+B_{t}
$$

Given lump-sum taxes, Ricardian equivalence holds and the only assumption that taxes are required to satisfy is that their present value is consistent with solvency.

\subsubsection{Goods market clearing}

Aggregating the budget constraint (12) across households and combing with the government budget constraint (21) yields the goods market clearing condition:

$$
Y_{t}=C_{t}+F_{t}+G_{t}+a\left(u_{t}\right) \bar{K}_{t-1}
$$

Equation (22) states that final output is absorbed by private consumption, investment and government spending. In addition, a fraction of final output is used to cover the capital utilization cost.

\subsection{Parameterization}

This section discusses the parameter values employed for the model simulation. In what follows we consider a log-linearized approximation of the model around the deterministic steady state in which inflation $\pi=0$. Each period corresponds to a quarter.

We choose conventional values for households' preference parameters and set the inverse of the elasticity of labor supply $\varphi$ equal to 1 and the discount factor $\beta$ equal to 0.995. The latter corresponds to a steady state real interest of around 2 per cent per year. The degree of habit in consumption $\gamma$ is equal to 0.75 as in Del Negro et al. (2007); we set $\lambda_{f}=0.15$ and $\lambda_{w}=0.05$, implying steady-state price and wage mark-ups equal to respectively 15 and 5 per cent. We set $\alpha$ to a standard value of 0.33 and the capital depreciation rate $\delta$ to 0.025 to match an investment-output ratio of 24 per cent. 
We set $\zeta_{p}=0.75$ implying firms can change price on average once a year, consistent with the results documented in Nakamura and Steinsson (2008) and in Bils and Klenow (2004). The wage stickiness parameter $\zeta_{w}$ is also equal to 0.75 , in line with the finding of the most recent empirical literature. ${ }^{11}$ Following Christiano et al. (2010) we assume full wage indexation to past inflation $\left(\iota_{w}=1\right)$.

We set the curvature of the investment adjustment cost $S^{\prime \prime}(1)$ equal to 14.30 following Christiano et al. (2010). The curvature of the capital utilization cost $a^{\prime \prime}$ is 0.035 , which implies, as in Smets and Wouters (2007), that in response to a 1 per cent increase in the rental rate of capital the utilization rate rises by 0.85 per cent.

The two LBD parameters, $\mu_{n}$ and $\rho_{x}$, are taken from Chang et al. (2002), who estimated them on the PSID. They are equal to respectively 0.111 and 0.797.

The autocorrelation coefficient for government spending $\rho_{g}$ is set to 0.90 as in Galí et al. (2007). The steady-state share of government spending is assumed to be 0.20 corresponding to the post-war period average.

For the specification of the monetary policy rule we use values from Christiano et al. (2014) and set $\phi_{\pi}=2.40, \phi_{\Delta y}=0.36$ and $\rho_{r}=0.85$.

Table 1 summarizes the values of all parameters.

\section{Illustrating the transmission mechanism in a sim- plified model}

We now simulate the model to analyze the response of quantities and prices to a shock to government spending. Before turning to the full-fledged model described in Section 3, we consider a simplified version of the model to illustrate the mechanisms through which

\footnotetext{
${ }^{11}$ Barattieri et al. (2010) find that on average the probability of a wage change is 18 per cent per quarter, implying an expected duration of wage contracts of about 5.6 quarters and corresponding to a value of $\zeta_{w}$ equal to 0.82 . Gottschalk (2005) finds that the probabilities of a wage change differ between males and females and are respectively equal to 46.3 and 53.5 per cent per year. This would imply a value for $\zeta_{w}$ around 0.87. Schmitt-Grohé and Uribe (2011) find a degree of downward inflexibility in nominal wages which corresponds to a value for $\zeta_{w}$ of around 1 .
} 
introducing LBD can bring the responses of consumption, measured TFP and real wages to a government spending shock more in line with the data.

For the simplified version of the model, we turn off habit formation in consumption $(\gamma=0)$ and wage indexation $\left(\iota_{w}=0\right)$. We also assume the monetary authority targets only current inflation $\left(\rho_{r}=\phi_{\Delta y}=0\right)$ and that the production function for intermediate goods does not use capital and is linear in labor $(\alpha=0)$.

In what follows, small letters denote the logarithm of variables and carets denote a variable's log-deviation from its steady state value.

Optimal household behavior yields the standard Euler equation

$$
\widehat{c}_{t}=\mathbb{E}_{t}\left[\widehat{c}_{t+1}\right]-\left(\widehat{i}_{t}-\mathbb{E}_{t}\left[\widehat{\pi}_{t+1}\right]\right)
$$

whereas, from firms' first order conditions it is possible to derive the New-Keynesian Phillips Curve

$$
\widehat{\pi}_{t}=\beta \mathbb{E}_{t}\left[\widehat{\pi}_{t+1}\right]+\frac{\left(1-\zeta_{p}\right)\left(1-\beta \zeta_{p}\right)}{\zeta_{p}} \widehat{m c}_{t}
$$

Integrating forward equations (23) and (24) yields

$$
\widehat{c}_{t}=-\mathbb{E}_{t} \sum_{s=0}^{\infty}\left(\widehat{i}_{t+s}-\widehat{\pi}_{t+1+s}\right)
$$

and

$$
\widehat{\pi}_{t}=\frac{\left(1-\zeta_{p}\right)\left(1-\beta \zeta_{p}\right)}{\zeta_{p}} \mathbb{E}_{t} \sum_{s=0}^{\infty} \beta^{s} \widehat{m c}_{t+s}
$$

where

$$
\widehat{m c}_{t}=\widehat{w}_{t}-\widehat{x}_{t}
$$

Equation (25) states that current consumption is negatively related to the sum of current and future short-term real interest rates. Note that by the expectation hypothesis this sum is equal, up to a first-order approximation, to the real rate of return on a hypothetical bond of infinite duration. Thus, the consumption dynamics is driven by 
the inter-temporal effect working through the real, long-term interest rate. A positive government shock can increase consumption only if it reduces the long-term real rate. However, if monetary policy follows a Taylor rule the reduction can occur only if inflation falls below its steady state level. By equation (26) current inflation depends on the discounted sum of the real marginal costs which, given linear technology, can only change in response to changes in the real wage, or the stock of knowledge (equation (27)).

Figure 3 compares impulse responses to an exogenous increase in government expenditure for the simplified model with (black solid line) and without (red dashed line) LBD. The responses of the nominal interest rate and inflation are measured as annualized percentage-point deviations from their steady state levels. The remaining variables are expressed in quarterly percentage deviations from their steady state level. The TFP panel in the figure plots the (log-) stock of skills $x_{t}$ which is the model counterpart of Fernald's (2012) measure of productivity in the data.

The increase in government spending results in an increase in the present value of taxes to satisfy the government inter-temporal budget constraint. Since leisure and consumption are normal goods, the resulting negative wealth effect induces agents to reduce both, causing an outward shift in the labor supply curve both with and without LBD. In both cases, TFP, is unchanged in the initial period $-\widehat{x}_{0}=0$.

In the economy without LBD, TFP is constant in all periods and the increase in present and future real wages raises present and future marginal costs and the rate of inflation in equation (26). The monetary authority reacts by increasing the (nominal) policy rate which, since the Taylor principle is satisfied, translates into an increase in the real short-term interest rate. It follows from the expectation hypothesis that the anticipated increase in future real short-term rates is immediately reflected in a higher long-term real rate which, by equation (25), brings about an inter-temporal effect that induces households to reduce consumption. The equilibrium response of the real wage is small since it only reflects the fall in the price markup associated with the Keynesian mechanism. 
In the economy with LBD, instead, the increase in hours worked increases the future skill level of the labor force and, therefore, future TFP. By equation (27) the increase in future TFP offsets, unlike in the case without LBD, the effect of the increase in real wages on marginal costs. In our parameterization the effect is large enough to reduce future marginal costs. It follows from equation (26) that the rate of inflation falls and therefore, by the Taylor principle, so do the policy rate and the short-term real interest rate. Since the fall in real short-term rates is persistent, it is reflected in a temporary fall in the long-term real rate and, by equation (25), an associated increase in consumption. Note, that relative to the case without LBD, the negative wealth effect is milder because the increase in future TFP raises the present value of real wages. Thus the labor supply curve shifts out less and the real wage increases more already in the first period.

To summarize, in the economy with LBD an exogenous increase in government expenditure initially crowds in, rather than out, private consumption, boosts TFP and the real wage, and reduces inflation. While all these responses are in line with our findings in Section 2.2 and those of the papers we cite there (in particular Jørgensen and Ravn, 2018; Hall and Thapar, 2018), it is worth emphasizing that the model transmission mechanism is very different from what Dupor and Li (2015) call the "expected-inflation channel" which is typical of all New-Keynesian models. According to this mechanism, an increase in government spending results in higher expected inflation and a lower real interest, and therefore higher consumption, if the central bank is non-responsive to inflation; i.e., if it raises the policy rate by less than the increase in expected inflation (Eggertsson, 2011; Christiano et al., 2011; Woodford, 2011). Instead the transmission channel in our model works through a fall in expected inflation to which the central bank responds by reducing the policy rate and, by the Taylor principle, the real rate.

So far we have emphasized the role of the long-term interest rate in accounting for the difference in response between the two economies. One may wonder the extent to which a similar response of consumption to a government expenditure shock might apply to the original set-up in Chang et al. (2002) featuring no nominal rigidities. To clarify 
this point, we compare the predictions of our simplified LBD model economy with and without nominal rigidities.

Figure 4 presents the results. The black solid lines plot the responses for the baseline case with nominal frictions and the red dashed lines correspond to the case without nominal frictions. The latter model cannot generate any increase in consumption. In fact, not only does consumption initially fall, it does so much more than in the model with nominal frictions but without LBD. To understand the economic intuition consider the following equilibrium condition

$$
m \widehat{p} n_{t}=\widehat{x}_{t}=\widehat{\mu}_{t}+\widehat{h}_{t}+\widehat{c}_{t}
$$

where $m p n_{t}$ denotes the $(\log )$ of the marginal product of labor, which, given the linear technology, can change only if the stock of knowledge $x_{t}$ does. The term $h_{t}+c_{t}$ is the $(\log )$ marginal rate of substitution between consumption and leisure. The variable $\mu_{t}$ is thus the wedge between the marginal rate of substitution and the marginal product of labor, and can be interpreted as the sum of the (log) wage and price markups. In the absence of nominal rigidities markups are constant and $\widehat{\mu}_{t}=0$. Since, the stock of knowledge $x_{t}$ is a state variable, the marginal product of labor is unchanged in the initial period. Therefore, as output and hours increase, consumption has to fall for the equilibrium condition (28) to hold. It follows from equation (25) that the long run real interest rate has to increase to crowd out consumption. Nominal rigidities are therefore essential for consumption to initially increase in response to a fiscal expansion; i.e., a fall in $\mu_{t}$ is a necessary condition for this to happen. From a different perspective, with flexible prices, the increase in TFP does not result in a fall in marginal cost, ${ }^{12}$ as it is fully reflected in a rise in the real wage. As a result, the key propagation mechanism from lower marginal cost to lower inflation and real interest rates is shut down.

\footnotetext{
${ }^{12}$ Note that we do not plot the impulse response for inflation and marginal cost under flexible prices in Figure 4 since both variables are unchanged in that case.
} 


\section{Simulation results for the full model}

We now turn to the simulation results for the complete model presented in section 3 , which allows for decreasing marginal returns to labor, capital dynamics and a more empirically plausible monetary rule. Figure 5 plots the impulse responses to an exogenous increase in government expenditure for the full-fledged model with (black solid line) and without (red dashed line) LBD. Compared to the results for the simplified economy in Figure 3, decreasing marginal returns to labor dampen the fall in the present value of marginal costs. As a result, the fall in inflation and the policy rate is delayed. This, together with the capital dynamics and variable capital utilization, generates a hump-shaped, as well as larger and much more persistent, increase in consumption. The full model also implies an increase in the level of investment stemming from the combination of higher labor productivity and lower real interest rates.

It is worth emphasizing that these effects are strictly due to the increase in measured TFP associated with the LBD mechanism. Absent this effect, in contrast with the empirical evidence, a government spending increase would have a negative effect on labor productivity and the real wage at all horizons and cause a counter-factual sizable fall in private consumption.

We have also studied the robustness of our findings to alternative parameterizations. In the interest of space, we report them in the Online Appendix. We highlight here the main takeaways. The response of consumption, the real wage, TFP and inflation are not significantly affected by a fall in the degree of price rigidity up to 0.25 . The response of consumption, instead, becomes negative for value of the degrees of wage rigidity below 0.5. Yet, for a degree of wage rigidity up to 0.25 the fall in consumption remains small, in line with empirical estimates. The response of consumption remains positive or negative, but small in absolute value, for a large range of parameters of the LBD mechanism and of the monetary policy reaction function.

Finally, the response of consumption remains positive for the values of the government 
spending persistence parameter $\rho_{g}$ up to 0.95 . Above such value consumption falls as the negative wealth effect associated with increased taxation more than offsets the Keynesian mechanism underpinning our main result.

\section{Conclusion}

This paper contributes to the ongoing debate on the short-run effects of fiscal policy on economic activity. We use a structural VAR analysis to identify the effects of government spending on output, consumption, TFP and the real wage. Consumption, TFP and the real wage respond positively to an exogenous increase in government expenditure, while inflation falls. This pattern of co-movement is consistent with a substantial body of empirical evidence but poses a puzzle for both neoclassical and New-Keynesian models with intertemporally-optimizing agents.

We show that introducing skill accumulation through work experience, in the form of learning-by-doing as modeled by Chang et al. (2002), into a standard New-Keynesian model à la Smets and Wouters (2007) can generate a transmission mechanism that is consistent with the empirical evidence. A positive shock to government spending increases hours and, through the learning-by-doing mechanism, induces skill accumulation and higher labor productivity and real wages in subsequent periods. Under parameter configurations that are both plausible and standard in the literature, the increase in future productivity lowers future marginal costs and therefore the expected rate of inflation. The fall in expected inflation results in a persistent reduction in the policy rate and the short-term real interest rates and, therefore, lowers the long-term real interest rate and increases consumption.

Interestingly, the learning-by-doing mechanism of Chang et al. (2002) provides a theoretic foundation for the hysteresis channel - the feedback from actual to potential output - assumed in DeLong and Summers (2012). Within this framework, we show that the existence of wage and price rigidities provides an important amplification mechanism. 
A potentially interesting research question is whether such mechanism provides sufficient amplification for a debt-financed increase in government purchases to be self-financing in the presence of distortionary taxation as is the case in DeLong and Summers (2012).

\section{References}

Auerbach, Alan J. and Yuriy Gorodnichenko (2012), 'Measuring the output responses to fiscal policy', American Economic Journal: Economic Policy 4(2), 1-27.

Bachmann, Rüdiger and Eric R. Sims (2012), 'Confidence and the transmission of government spending shocks', Journal of Monetary Economics 59(3), 235 - 249.

Barattieri, Alessandro, Susanto Basu and Peter Gottschalk (2010), Some evidence on the importance of sticky wages, NBER Working Papers 16130, National Bureau of Economic Research, Inc.

Baxter, Marianne and Robert G. King (1993), 'Fiscal policy in general equilibrium', The American Economic Review 83(3), 315-334.

Ben Zeev, Nadav and Evi Pappa (2015a), 'Chronicle of a war foretold: The macroeconomic effects of anticipated defense spending shocks', The Economic Journal .

Ben Zeev, Nadav and Evi Pappa (2015b), 'Multipliers of unexpected increases in defense spending: An empirical investigation', Journal of Economic Dynamics and Control 57(C), 205-226.

Bianchi, Francesco, Howard Kung and Gonzalo Morales (2017), Growth, slowdowns, and recoveries. Mimeo.

Bilbiie, Florin O. (2009), 'Nonseparable preferences, fiscal policy puzzles, and inferior goods', Journal of Money, Credit and Banking 41(2-3), 443-450.

Bils, Mark and Peter J. Klenow (2004), 'Some evidence on the importance of sticky prices', Journal of Political Economy 112(5), 947-985. 
Blanchard, Olivier and Roberto Perotti (2002), 'An empirical characterization of the dynamic effects of changes in government spending and taxes on output', The Quarterly Journal of Economics 117(4), 1329-1368.

Burnside, Craig, Martin Eichenbaum and Jonas D.M. Fisher (2004), 'Fiscal shocks and their consequences', Journal of Economic Theory 115(1), 89 - 117.

Caldara, Dario and Christophe Kamps (2008), What are the effects of fiscal shocks? a VAR-based comparative analysis, Working Paper Series 877, European Central Bank.

Calvo, Guillermo A. (1983), 'Staggered prices in a utility-maximizing framework', Journal of Monetary Economics 12(3), 383-398.

Canova, Fabio and Evi Pappa (2007), 'Price differentials in monetary unions: The role of fiscal shocks', Economic Journal 117(520), 713-737.

Chang, Yongsung, Joao F. Gomes and Frank Schorfheide (2002), 'Learning-by-doing as a propagation mechanism', American Economic Review 92(5), 1498-1520.

Christiano, Lawrence J., Martin Eichenbaum and Charles L. Evans (2005), 'Nominal rigidities and the dynamic effects of a shock to monetary policy', Journal of Political Economy 113(1), 1-45.

Christiano, Lawrence J., Mathias Trabandt and Karl Walentin (2010), DSGE models for monetary policy analysis, in B. M.Friedman and M.Woodford, eds, 'Handbook of Monetary Economics', Vol. 3 of Handbook of Monetary Economics, Elsevier, chapter 7, pp. $285-367$.

Christiano, Lawrence J., Roberto Motto and Massimo Rostagno (2014), 'Risk shocks', American Economic Review 104(1), 27-65.

Christiano, Lawrence, Martin Eichenbaum and Sergio Rebelo (2011), 'When is the government spending multiplier large?', Journal of Political Economy 119(1), 78-121. 
Corsetti, Giancarlo, André Meier and Gernot Müller (2012), 'Fiscal stimulus with spending reversals', Review of Economics and Statistics 94(4), 878-895.

Del Negro, Marco, Frank Schorfheide, Frank Smets and Rafael Wouters (2007), 'On the fit of New Keynesian models', Journal of Business 83 Economic Statistics 25, 123-143.

DeLong, J. Bradford and Lawrence H. Summers (2012), Fiscal policy in a depressed economy, Brookings papers on economic activity, spring 2012, The Brookings Institution.

Devereux, Michael B., Allen C. Head and Beverly J. Lapham (1996), 'Monopolistic competition, increasing returns, and the effects of government spending', Journal of Money, Credit and Banking 28(2), 233-54.

Dupor, Bill and Rong Li (2015), 'The expected inflation channel of government spending in the postwar U.S.', European Economic Review 74, 35-56.

Edelberg, Wendy, Martin Eichenbaum and Jonas D.M. Fisher (1999), 'Understanding the effects of a shock to government purchases', Review of Economic Dynamics 2(1), 166 $-206$.

Eggertsson, Gauti B. (2011), What fiscal policy is effective at zero interest rates?, in 'NBER Macroeconomics Annual 2010, Volume 25', National Bureau of Economic Research, Inc, pp. 59-112.

Engler, Philipp and Juha Tervala (2016), Hysteresis and fiscal policy. Mimeo.

Ercolani, Valerio and Nicola Pavoni (2016), The precautionary saving effect of government consumption. Mimeo.

Fatás, Antonio and Ilian Mihov (2001), The effects of fiscal policy on consumption and employment: Theory and evidence, CEPR Discussion Papers 2760, C.E.P.R. Discussion Papers.

Fernald, John (2012), 'A quarterly, utilization-adjusted series on total factor productivity', Manuscript, Federal Reserve Bank of San Francisco . 
Galí, Jordi, J. David López-Salido and Javier Vallés (2007), 'Understanding the effect of government spending on consumption', Journal of the European Economic Association $5(1), 227-270$.

Giannone, Domenico, Michele Lenza and Giorgio E. Primiceri (2015), 'Prior selection for vector autoregressions', The Review of Economics and Statistics 97(2), 436-451.

Glomm, Gerhard and B. Ravikumar (1997), 'Productive government expenditures and long-run growth', Journal of Economic Dynamics and Control 21(1), 183 - 204.

Gnocchi, Stefano, Daniela Hauser and Evi Pappa (2016), 'Housework and fiscal expansions', Journal of Monetary Economics 79, 94 - 108.

Gottschalk, Peter (2005), 'Downward nominal-wage flexibility: Real or measurement error?', The Review of Economics and Statistics 87(3), 556-568.

Hall, Matthew and Aditi Thapar (2018), The economic effects of government spending: The importance of controlling for anticipated information. Mimeo.

Hall, Robert (2009), 'By how much does gdp rise if the government buys more output?', Brookings Papers on Economic Activity 40(2), 183-249.

Jørgensen, Peter Lihn and Søren Hove Ravn (2018), The inflation response to government spending shocks: A fiscal price puzzle? Mimeo.

Linnemann, Ludger and Andreas Schabert (2006), 'Productive government expenditure in monetary business cycle models', Scottish Journal of Political Economy 53(1), 28-46.

Monacelli, Tommaso and Roberto Perotti (2008), Fiscal policy, wealth effects, and markups, Working Paper 14584, National Bureau of Economic Research.

Mountford, Andrew and Harald Uhlig (2009), "What are the effects of fiscal policy shocks?', Journal of Applied Econometrics 24(6), 960-992. 
Nakamura, Emi and Jón Steinsson (2008), 'Five facts about prices: A reevaluation of menu cost models', The Quarterly Journal of Economics 123(4), 1415-1464.

Nekarda, Christopher J. and Valerie A. Ramey (2011), 'Industry evidence on the effects of government spending', American Economic Journal: Macroeconomics 3(1), 36 - 59 .

Pappa, Evi (2009), 'The effects of fiscal shocks on employment and the real wage', International Economic Review 50(1), 217-244.

Perotti, Roberto (2008), In search of the transmission mechanism of fiscal policy, in 'NBER Macroeconomics Annual', Vol. 22 of NBER Chapters, National Bureau of Economic Research, Inc, pp. 169-226.

Ramey, Valerie A. (2011), 'Identifying government spending shocks: It's all in the timing', The Quarterly Journal of Economics 126(1), 1-50.

Ramey, Valerie A. and Matthew D. Shapiro (1998), 'Costly capital reallocation and the effects of government spending', Carnegie-Rochester Conference Series on Public Policy 48(0), $145-194$.

Ravn, Morten O., Stephanie Schmitt-Grohé and Martín Uribe (2012), 'Consumption, government spending, and the real exchange rate', Journal of Monetary Economics $\mathbf{5 9}(3), 215-234$.

Ravn, Morten, Stephanie Schmitt-Grohé and Martin Uríbe (2006), 'Deep habits', Review of Economic Studies 73(1), 195-218.

Rendahl, Pontus (2016), 'Fiscal policy in an unemployment crisis', The Review of Economic Studies 83, 1225-1262.

Rotemberg, Julio and Michael Woodford (1992), 'Oligopolistic pricing and the effects of aggregate demand on economic activity', Journal of Political Economy 100(6), 11531207. 
Schmitt-Grohé, Stephanie and Martín Uribe (2011), Pegs and pain, NBER Working Papers 16847, National Bureau of Economic Research, Inc.

Sims, Christopher and Tao Zha (1998), 'Bayesian methods for dynamic multivariate models', International Economic Review 39(4), 949-68.

Smets, Frank and Raf Wouters (2003), 'An estimated dynamic stochastic general equilibrium model of the euro area', Journal of the European Economic Association $\mathbf{1}(5), 1123-1175$.

Smets, Frank and Rafael Wouters (2007), 'Shocks and frictions in US business cycles: A bayesian dsge approach', American Economic Review 97(3), 586-606.

Woodford, Michael (2011), 'Simple analytics of the government expenditure multiplier', American Economic Journal: Macroeconomics 3(1), 1-35. 


\begin{tabular}{|ll|l|l|}
\hline \multicolumn{2}{|c|}{ Parameter } & Value & Target/Source \\
\hline$\varphi$ & Inverse labor supply elasticity & 1 & Standard value \\
$\beta$ & Discount factor & 0.995 & Annualized real interest rate: $2 \%$ \\
$\gamma$ & Consumption habit & 0.75 & Del Negro et al. (2007) \\
$\lambda_{f}$ & Price mark-up & 0.15 & Steady state price mark-up: 15\% \\
$\lambda_{w}$ & Wage mark-up & 0.05 & Steady state wage mark-up: 5\% \\
$\alpha$ & Capital share & 0.33 & Standard value \\
$\delta$ & Capital depreciation rate & 0.025 & Investment output ratio: 0.24 \\
$\zeta_{p}$ & Probability of fixed price & 0.75 & Average price duration: 4 qrts \\
$\zeta_{w}$ & Probability of fixed wage & 0.75 & Average wage duration: 4 qrts \\
$\iota_{w}$ & Degree of wage indexation & 1 & Full indexation to past inflation \\
$S^{\prime \prime}$ & Investment adjustment cost & 14.30 & Christiano et al. (2010) \\
$a^{\prime \prime}$ & Capital utilization cost & 0.035 & Smets and Wouters (2007) \\
$\mu_{n}$ & LBD: hours impact & 0.111 & Chang et al. (2002) \\
$\rho_{x}$ & LBD: auto-correlation & 0.797 & Chang et al. (2002) \\
$\rho_{g}$ & Auto-correlation of $G_{t}$ & 0.90 & Galí et al. (2007) \\
$\frac{G}{G D P}$ & $G / G D P$ ratio & 0.20 & Sample average \\
$\phi_{\pi}$ & Monetary rule: inflation & 2.40 & Christiano et al. (2014) \\
$\phi_{\Delta y}$ & Monetary rule: output growth & 0.36 & Christiano et al. (2014) \\
$\rho_{r}$ & Monetary rule: smoothing & 0.85 & Christiano et al. (2014) \\
\hline
\end{tabular}

Table 1: Parameter values used in the baseline medium-size DSGE model 

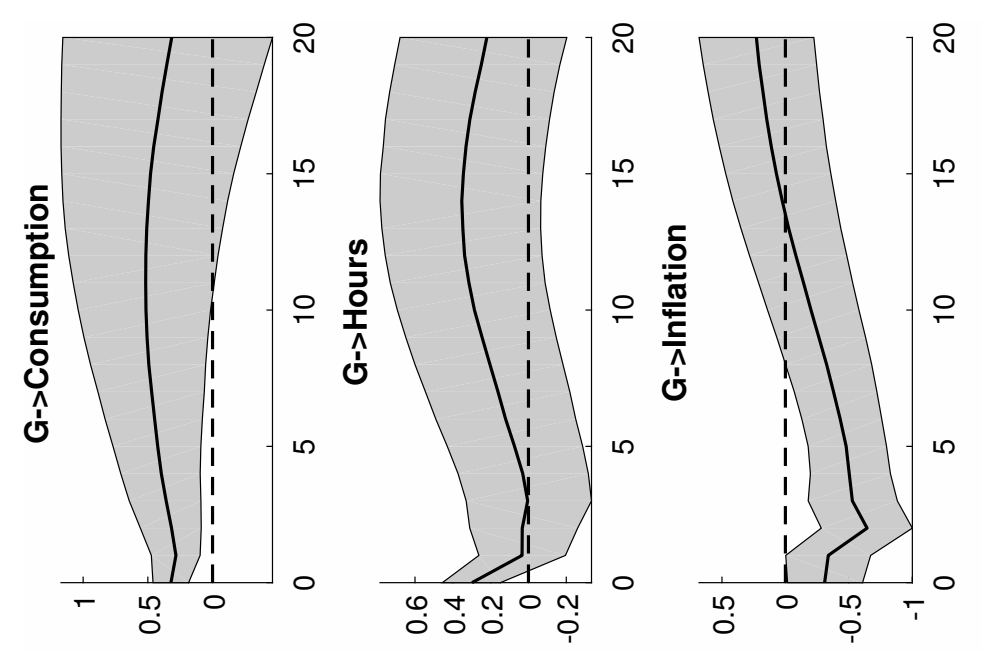

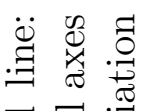

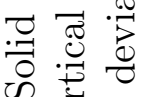

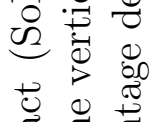

苋苛苞

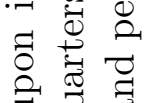

实

穴政

㓥

$\square$.

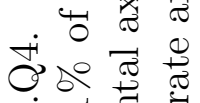

숭-

实它.

ชิ .900.

+

的凋

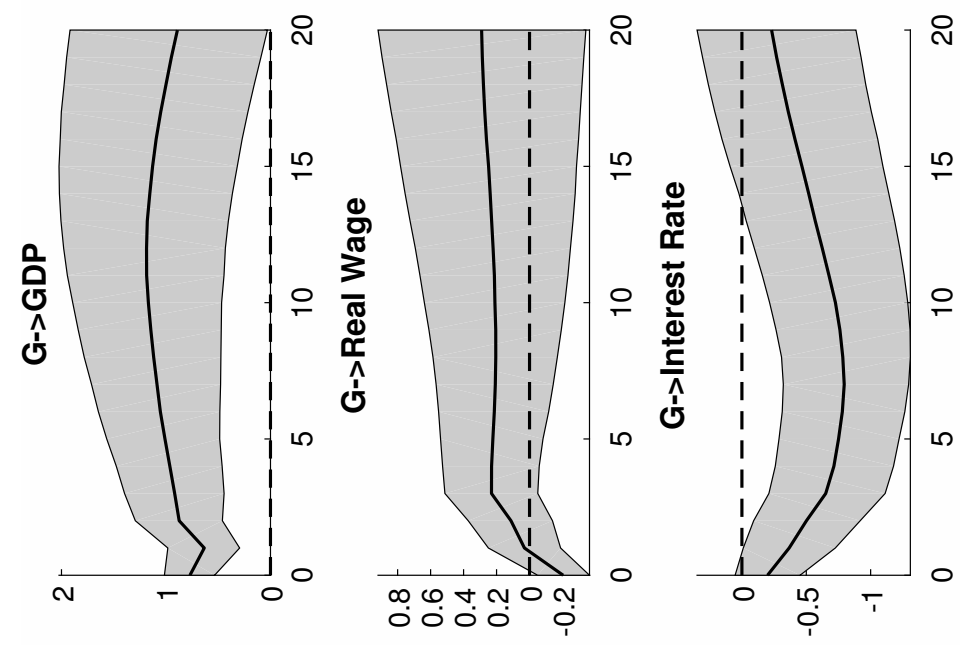

क o

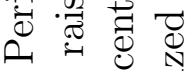

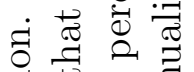

专

닝

氖

का

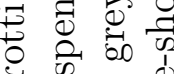

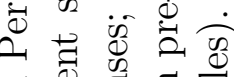

寻

政

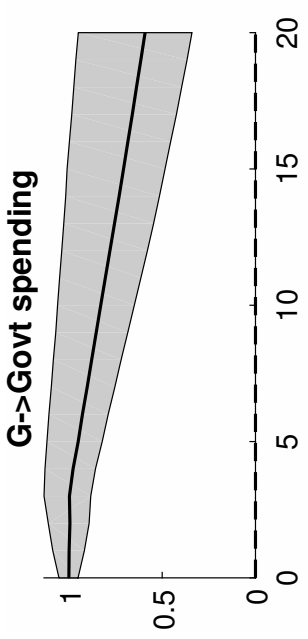

오

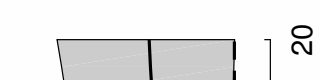

i

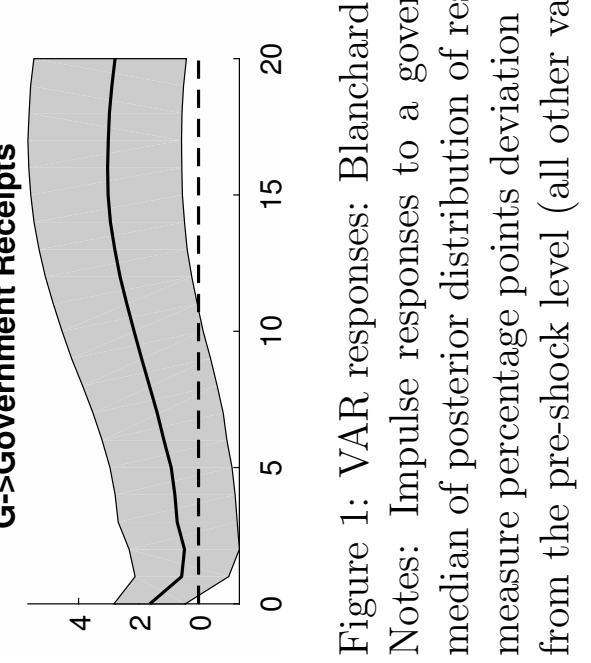



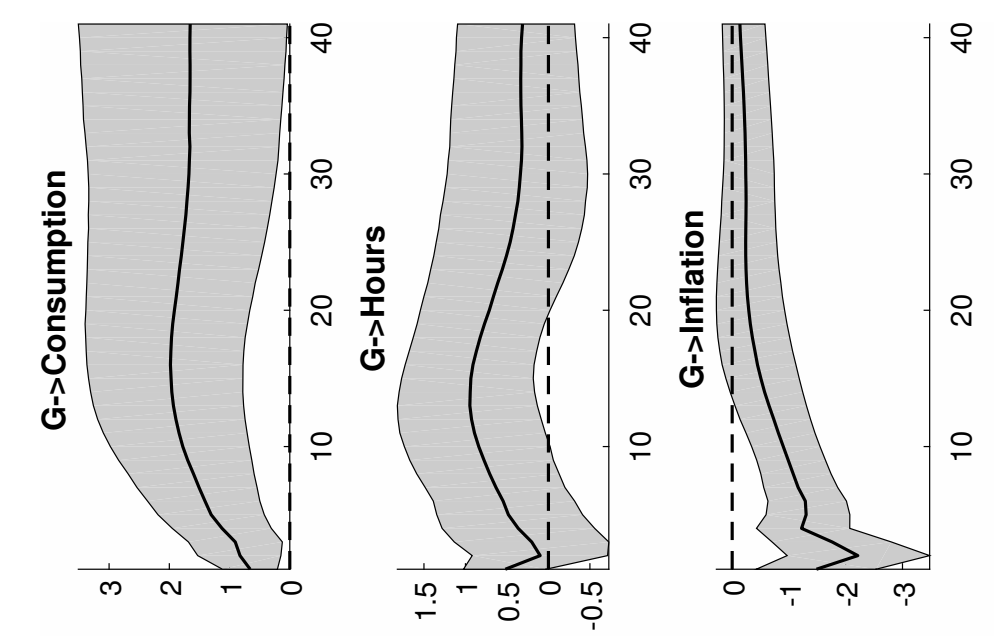

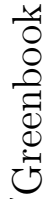

का

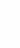

पे

苞
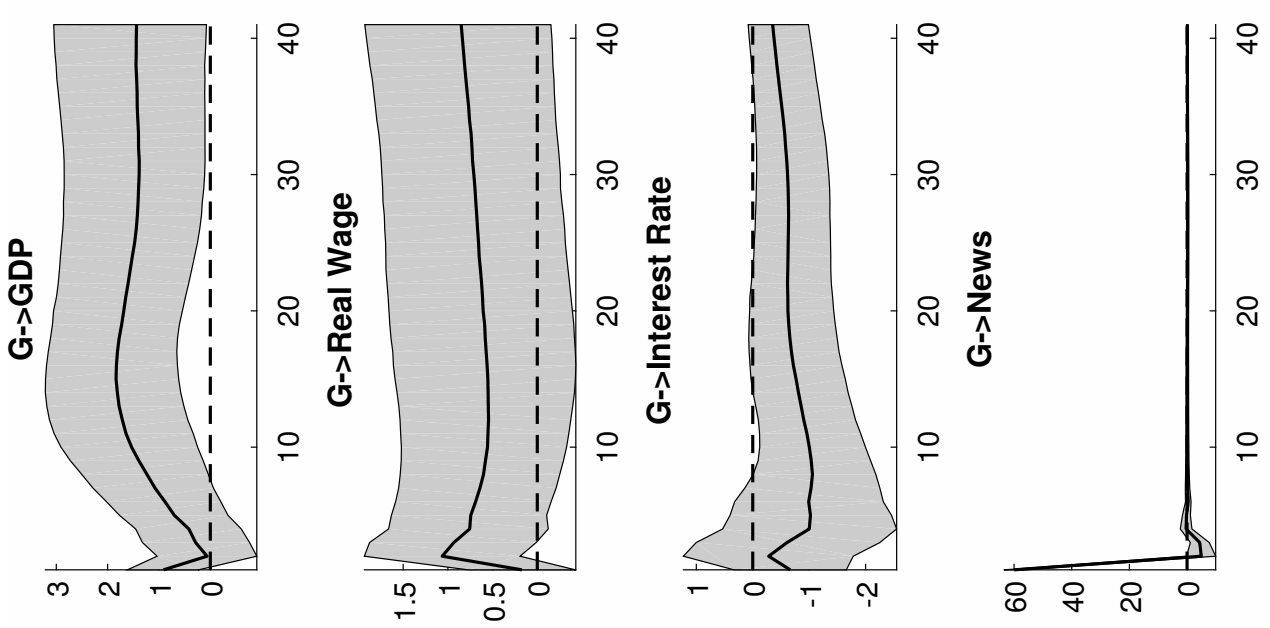

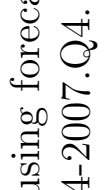

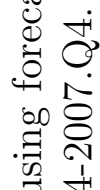

:

䓎

잉

过

营

is

월

可

$\begin{array}{ll} & \\ 0 & 0 \\ 0 & 0 \\ 0 & 0\end{array}$

సี

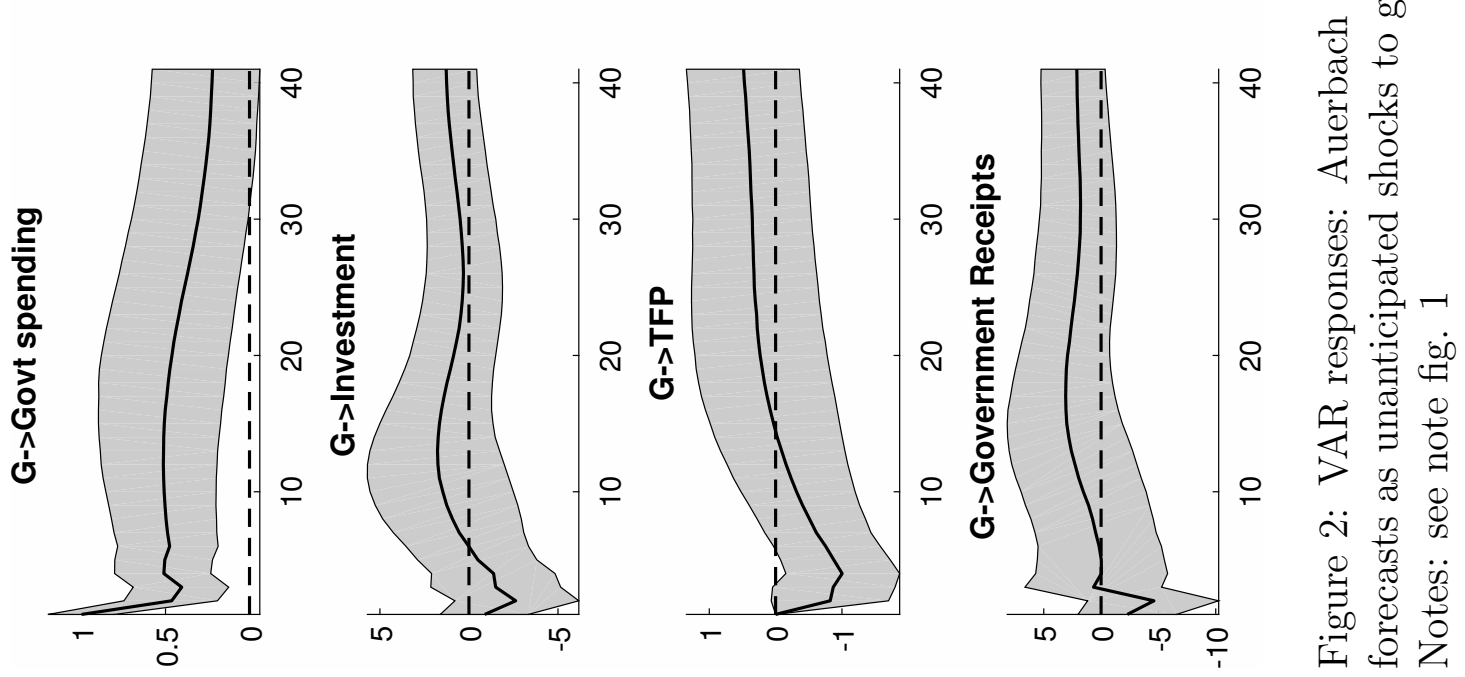



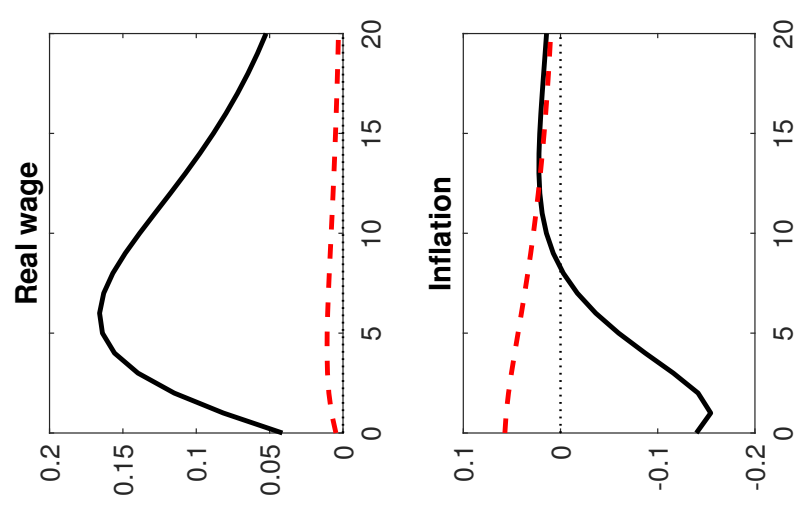

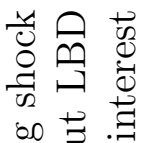

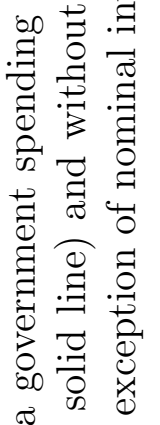

웜

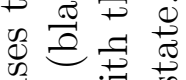

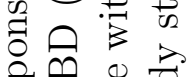

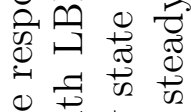
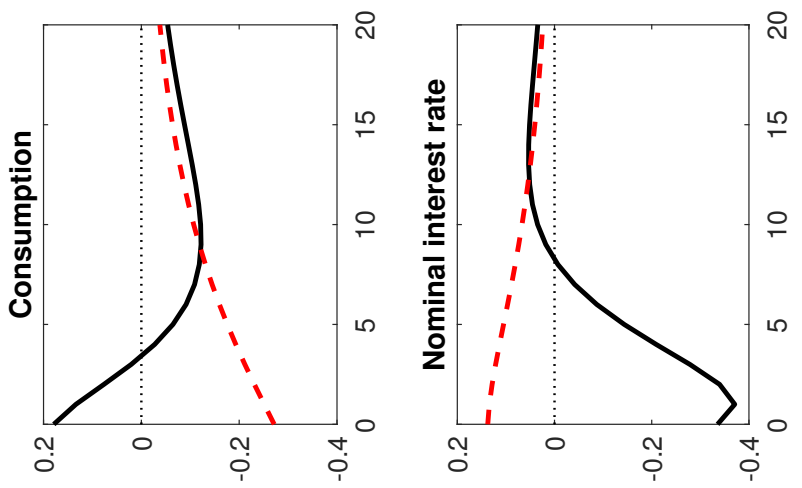

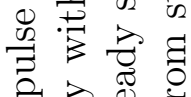

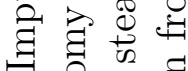

คิ

뭉 웜

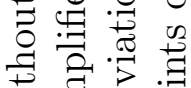

节贯总

चี

풍ㅎㅇ 풍
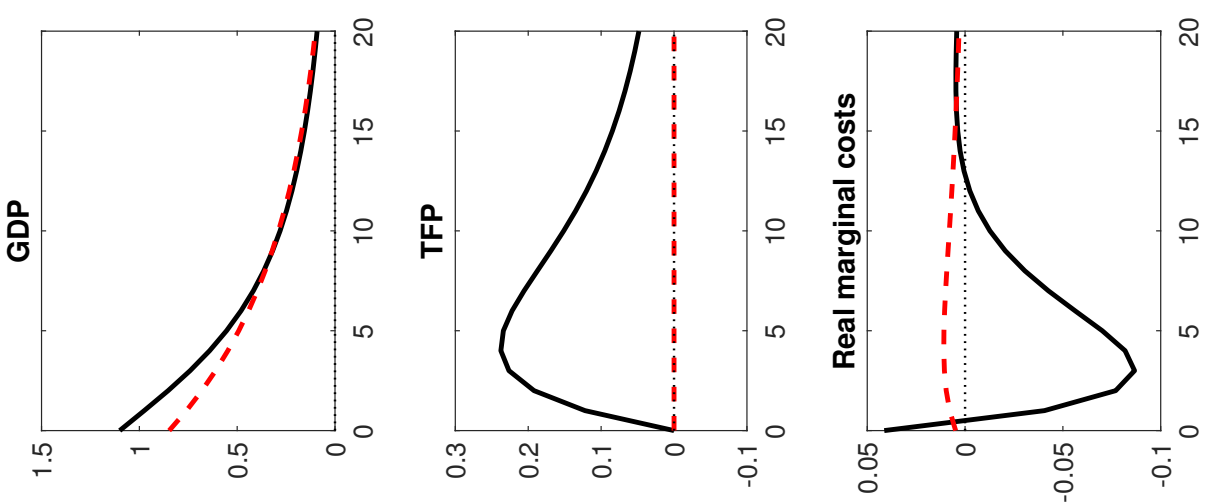

节

苋

द्व.

ठํ.

을

구엉

여워

क

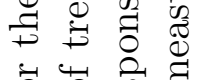

कै पे की
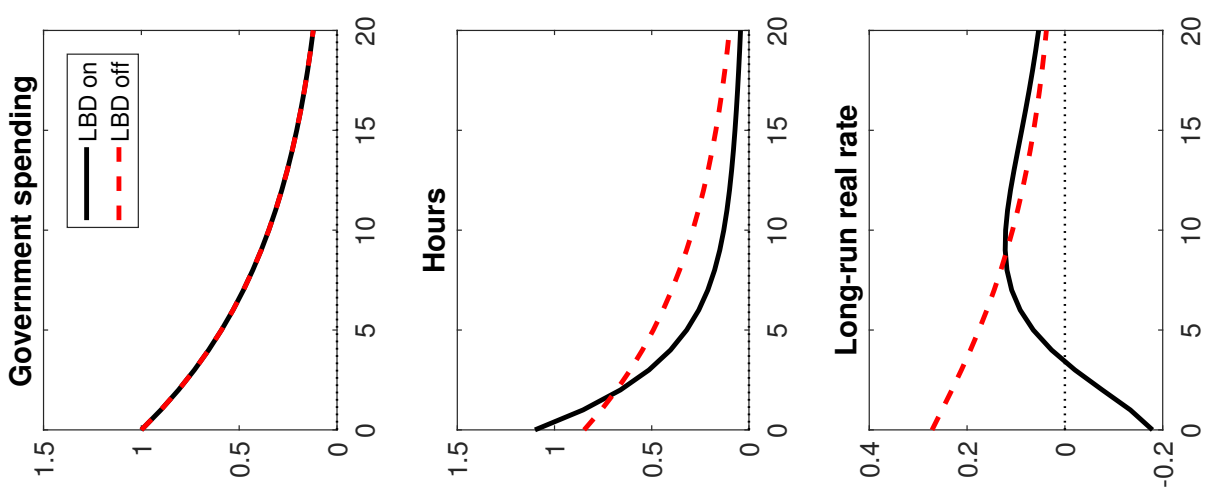

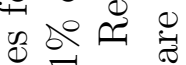

品

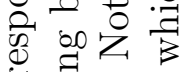

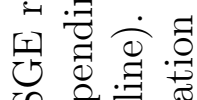

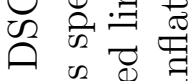

$\ddot{0}$.

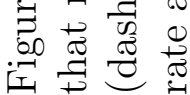



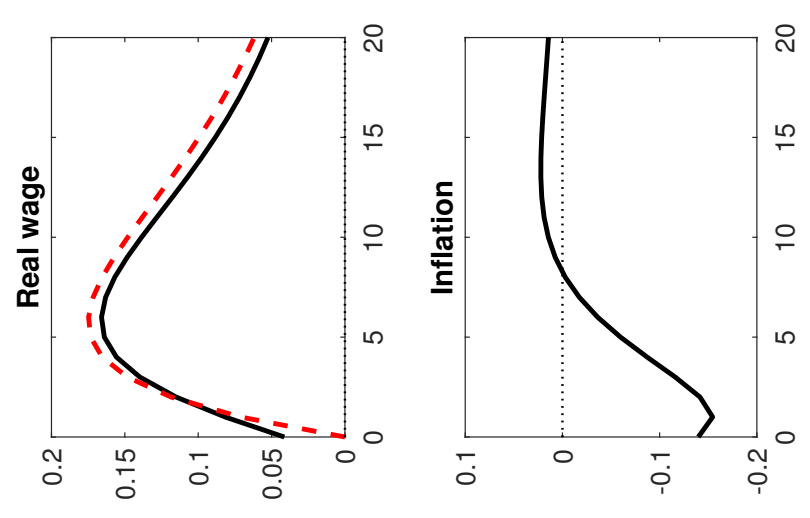

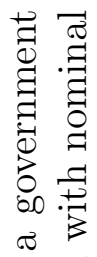

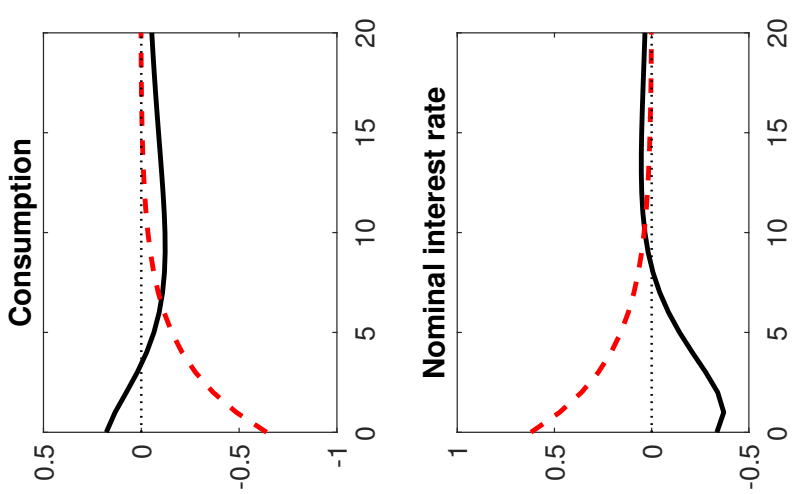

$\stackrel{\circ}{\circ}$

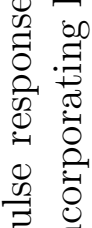

․ㅠ

छ

:

.

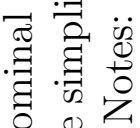

월

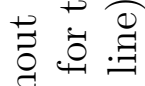

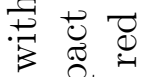

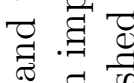

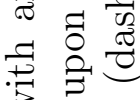
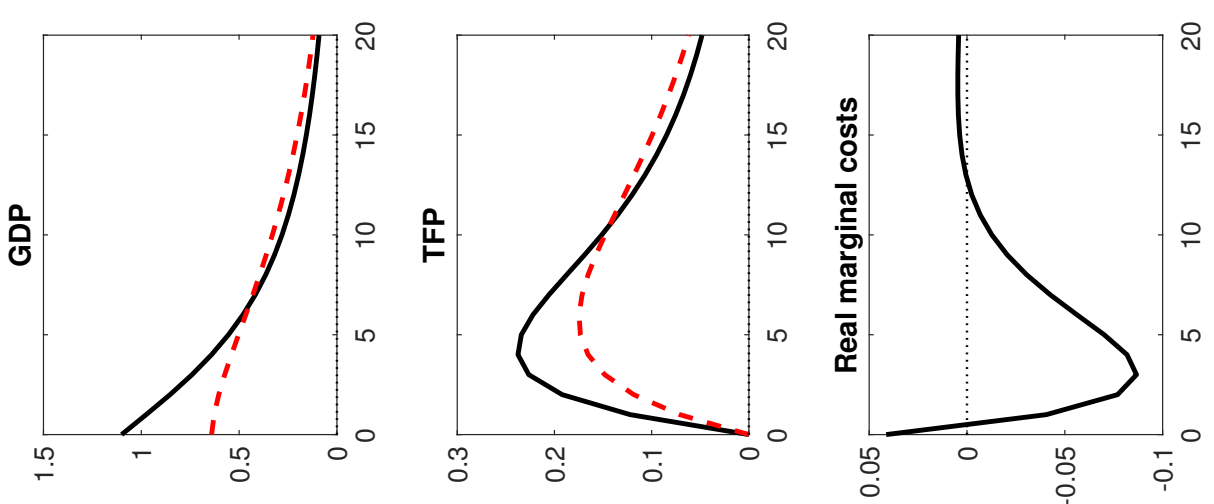

35 क

害宅

둥 ช

త్ర

금

灵合

임

苂
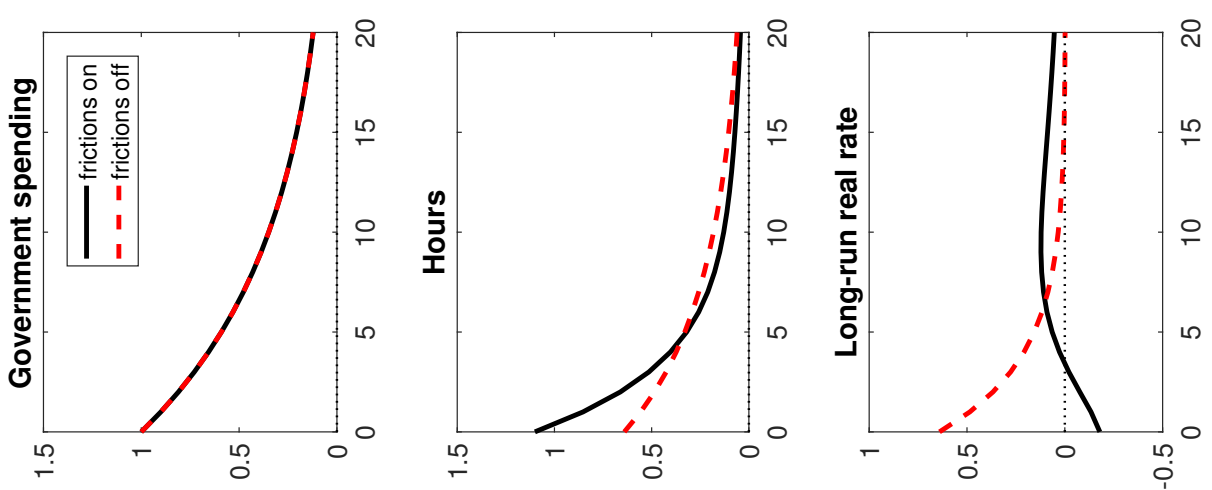

焉

ㄱ.

के

$\rightarrow$ 잉

된

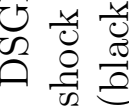

$\ddot{\forall} \stackrel{\infty}{0} \mathrm{~g}$

苟 :

点 0 

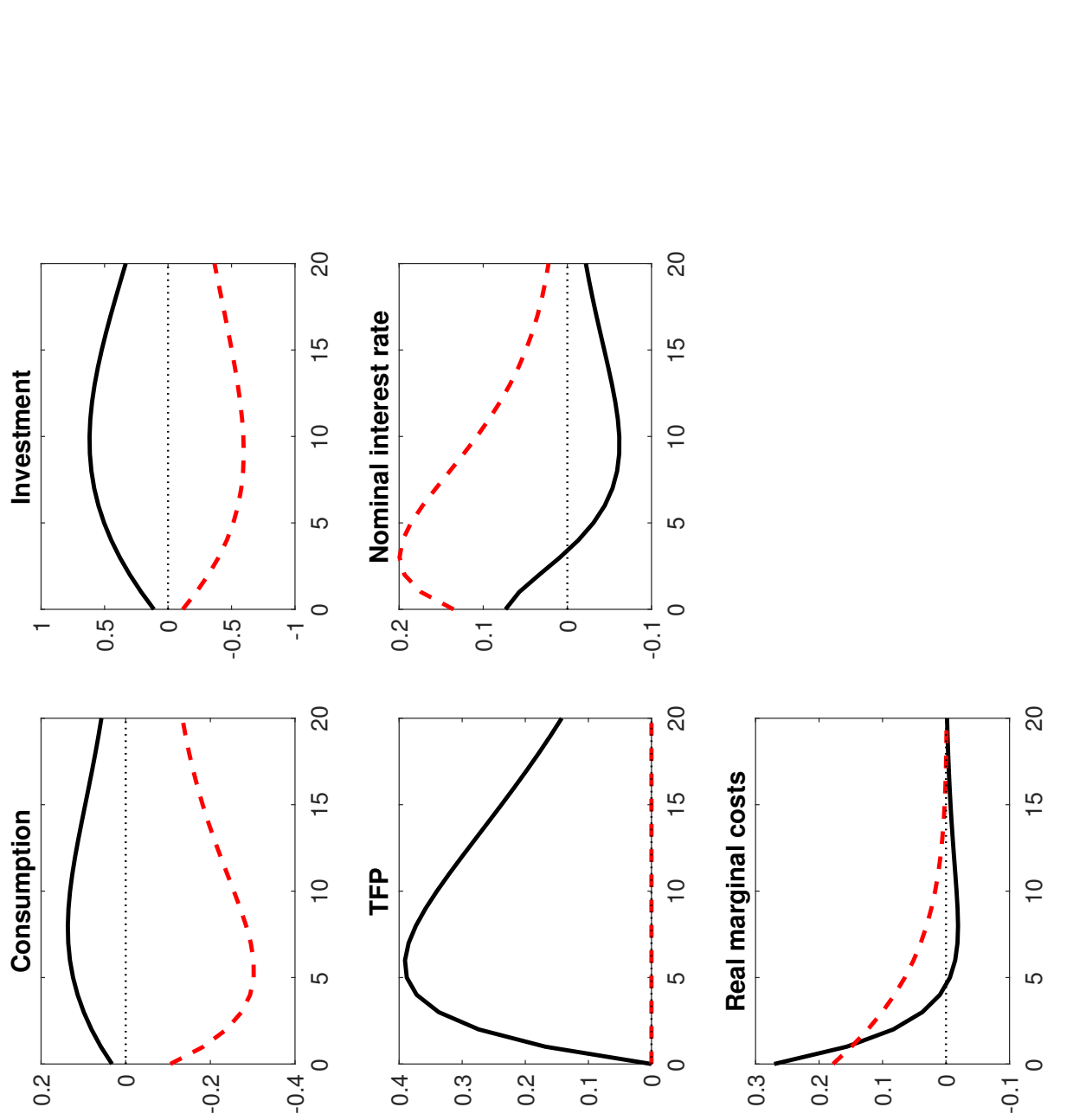

进佥

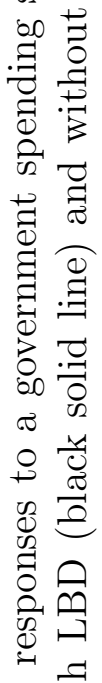
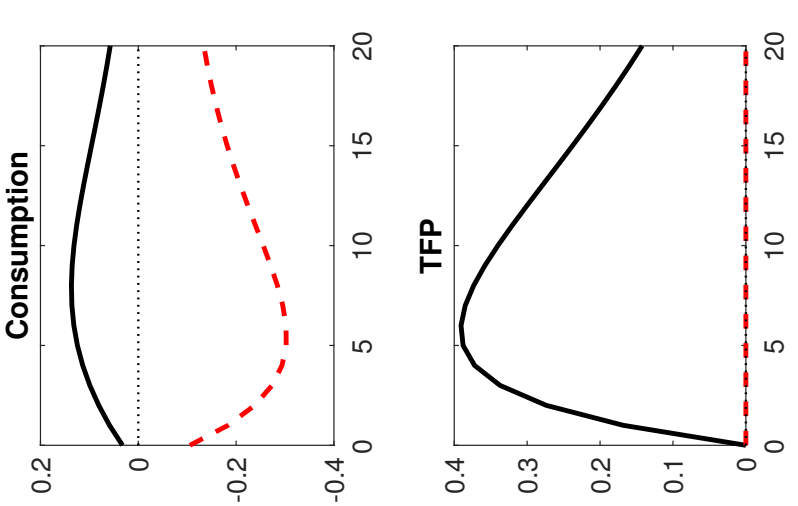

语高

音

คิ

48

营站

경
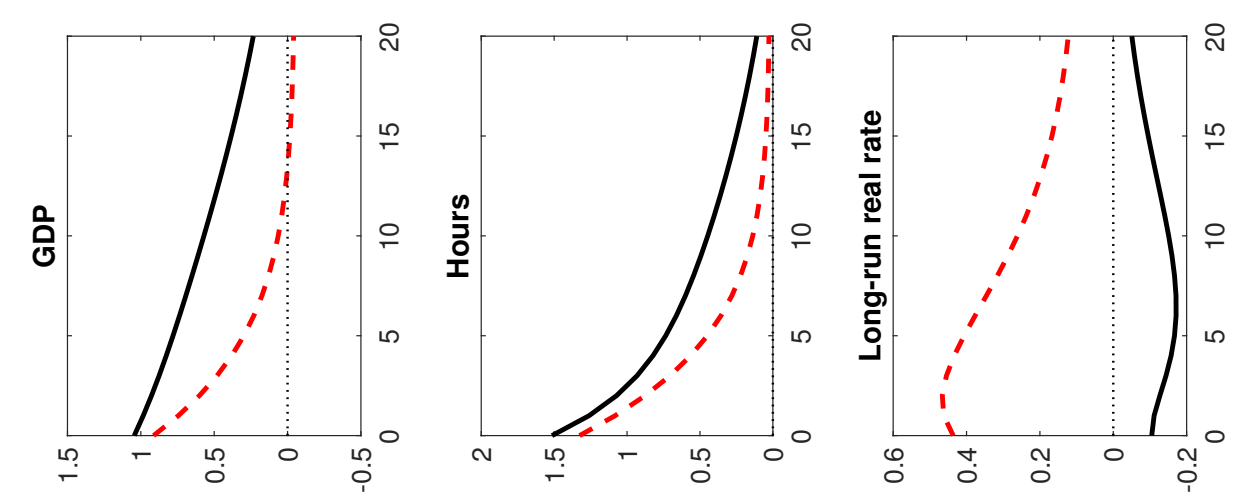

- 0
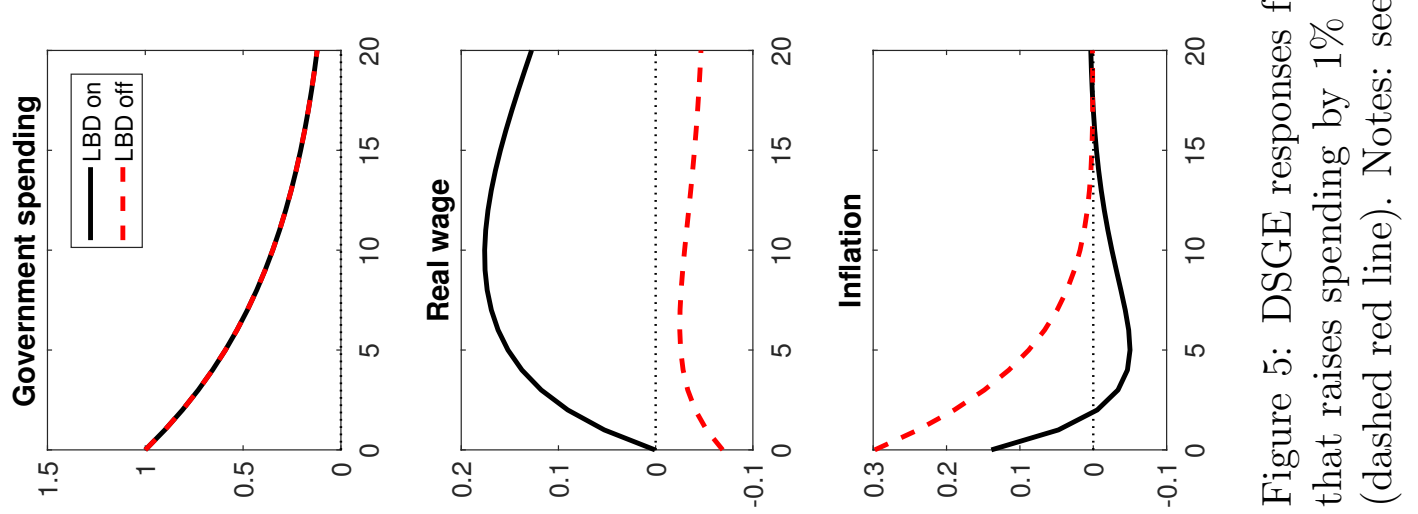


\section{SUPPLEMENTARY APPENDIX}

\section{A Robustness}

\section{A.1 Robustness of empirical results}

Our empirical analysis in Section 2 shows that a positive government expenditure shock, as identified by our assumptions, is associated with an increase in consumption and a fall in the real interest rate. One potential concern is that, to the extent that government spending predominantly countercyclical, our identification strategy may actually imply that our estimated impulse responses to the identified government spending shock may be contaminated by the response of variables to countercyclical monetary policy. ${ }^{13}$ In order to address the above concern, we explore here an alternative strategy which identifies government spending shocks as innovations to government spending that are: (a) contemporaneously orthogonal to TFP movements; (b) pre-determined with respect to all other variables in Z t; and (c) contemporaneously orthogonal to interest rate changes. While we already use (a) and (b) for our main identification strategy, (c) is added here to address the above concern. Figure 6 reports the impulse responses. Comparing them to those in Figure 1 makes clear that the responses of consumption, TFP, the real wage and inflation are qualitatively unaffected relative to the benchmark identification.

We have also assessed the robustness of our findings to alternative inflation and productivity measures. Specifically: (a) we have replaced the GDP deflator, our baseline measure of inflation, with the CPI; (b) we have replaced the series for TFP with the average labor productivity; (c) we have included commodity prices. For each case, we report impulse responses for the Blanchard-Perotti identification. Figures 7 to 9 plot the set of impulse responses. In line with a similar robustness exercise conducted by Jørgensen and Ravn (2018) with a frequentist approach, we find that inflation persistently falls in all cases. We also find that, qualitatively, the response of consumption, the real wage, and

\footnotetext{
${ }^{13}$ We are grateful to an anonymous referee for this suggestion.
} 
TFP is consistent with the findings in the main section.

\section{A.2 Robustness of model implications}

This section studies the robustness of our findings in the main text to alternative parameterizations and functional form assumptions.

Figure 10 shows the sensitivity of consumption to the parameters capturing, respectively, the impact of past hours $\left(\mu_{n}\right)$ and skill persistence $\left(\rho_{x}\right)$ in the LBD mechanism. The responses are reported for three different horizons: upon impact and after 4 and 16 quarters. The areas to the north-east of the yellow one contain the set of parameter value that generate a positive consumption response, while the areas to the south-west denote the combinations of the two parameters for which the consumption response is negative. The dot corresponds to the estimates by Chang et al. (2002) from the PSID that we use. The white area refers to the set of values for which the equilibrium is indeterminate. ${ }^{14}$ The figure shows that the response of consumption is positive for a reasonably large range of values.

Figure 11 displays the response of consumption at different horizons as a function of $\rho_{g}$, the parameter measuring the persistence of the government expenditure process. The response of consumption is positive for values of $\rho_{g}$ as large as 0.95. For higher values the negative wealth effect of a, close to permanent, government spending shock prevails. More interestingly, the response of consumption is increasing in $\rho_{g}$ up to a value of about 0.8 indicating that in that range the larger negative wealth affect associated with a higher $\rho_{g}$ is more than offset by the larger cumulative LBD response driven by the more persistent Keynesian demand effect.

Figures 12 and 13 show the response of the key variables for three alternative values of the degrees of price and wage rigidity $(0.25,0.5,0.85)$ as captured by the Calvo parameters $\zeta_{p}$ and $\zeta_{w}$. As expected, the response of consumption and the real wage are increasing in the degree of price and wage rigidity. Even for a low, by the literature's standard, value

\footnotetext{
${ }^{14}$ Appendix $\mathrm{C}$ discusses the implications of LBD for indeterminacy.
} 
of $\zeta_{p}=0.25$ the response of the real wage is positive, with the exception of the first two quarters. Similarly, consumption falls, though by a very small amount, in the first two quarters but increases at all other horizons. The sign of the response of the real wage is robust to changes in the degree of wage rigidity. On the other hand, the response of consumption is negative at all horizons for values of $\zeta_{w}$ below 0.5 . Its magnitude though is remarkably small, and substantially smaller than in the absence of LBD (cf. Figure 5), even for $\zeta_{w}=0.25$.

Figure 14 shows the response of consumption for a large range of parameter values for the monetary policy rule in equation (19). The response is positive nearly everywhere. Furthermore, the response is increasing in the size of $\phi_{\pi}$, the parameter controlling the response of the policy rate to the inflation forecast. As pointed out in Dupor and Li (2015), this result is in contrast with the standard transmission channel in New Keynesian models but in line with their findings, in the context of a structural VAR, that the response of consumption to a government expenditure shock is positive, and larger in periods in which the central bank responds more aggressively to inflation.

Finally, we assess the robustness of our findings in the case of an alternative monetary policy in which the GDP growth target in equation (19) is replaced by a target for the GDP level. Figure 15 plots the response of the key variables for alternative values $(0.05,0.15,0.25,0.35)$ of the coefficient on the deviation of output from steady state, while keeping all other parameters at their baseline value. The response of consumption is positive for values of the output-gap coefficient below 0.25 and, though negative, remains small in absolute value even when the coefficient equals 0.35 . Figure 16 shows the response of consumption for different combinations of inflation and output-gap coefficients in the monetary policy rule. Again, the response of consumption is either positive or negative, but remarkably small, for a large range of parameter combinations. 


\section{B Model derivation}

Apart from the inclusion of LBD, the model presented is a standard New-Keynesian DSGE model as employed in Smets and Wouters (2007). In this part we list the first order conditions, the steady state values and the set of log-linearized equations. In what follow the symbol " $\sim$ " denotes variables expressed in real term.

\section{B.1 First order conditions}

\section{B.1.1 Households.}

Since in equilibrium all households make the same decision, the $l$ index can be dropped. Households' first order conditions with respect to bond holding $B_{t}$, consumption $C_{t}$, investment $F_{t}$, capital $\bar{K}_{t}$ and capital utilization $u_{t}$ are:

$$
\begin{gathered}
\lambda_{t}^{I} \mathbb{E}_{t}\left[\pi_{t+1}\right]=\beta \mathbb{E}_{t}\left[\lambda_{t+1}^{I}\right] i_{t} \\
\lambda_{t}^{I}=\frac{1}{\left(C_{t}-\gamma C_{t-1}\right)}-\frac{\gamma \beta}{\left(\mathbb{E}_{t}\left[C_{t+1}\right]-\gamma C_{t}\right)} \\
\lambda_{t}^{I}=\lambda_{t}^{K}\left[1-S\left(\frac{F_{t}}{F_{t-1}}\right)-S^{\prime}\left(\frac{F_{t}}{F_{t-1}}\right) \frac{F_{t}}{F_{t-1}}\right]+\beta \mathbb{E}_{t}\left[\lambda_{t+1}^{K}\right]\left[S^{\prime}\left(\frac{\mathbb{E}_{t}\left[F_{t+1}\right]}{F_{t}}\right)\left(\frac{\mathbb{E}_{t}\left[F_{t+1}\right]}{F_{t}}\right)^{2}\right] \\
\lambda_{t}^{K}=\beta \mathbb{E}_{t}\left[\lambda_{t+1}^{I}\right]\left(\mathbb{E}_{t}\left[\tilde{R}_{t+1} u_{t+1}\right]-a\left(\mathbb{E}_{t}\left[u_{t+1}\right]\right)\right)+\beta(1-\delta) \mathbb{E}_{t}\left[\lambda_{t+1}^{K}\right] \\
(32) \\
\tilde{R}_{t}=a^{\prime}\left(u_{t}\right)
\end{gathered}
$$

where $\lambda_{t}^{I} \equiv P_{t} \bar{\lambda}_{t}^{I}$ and $\bar{\lambda}_{t}^{I}$ and $\lambda_{t}^{K}$ are the multipliers associated respectively to the budget constraint (12) and the capital evolution constraint (13). 


\section{B.1.2 Wage setting}

The first order condition for the wage setting problem described in (15) can be rearranged as:

$$
\begin{gathered}
\mathbb{E}_{t} \sum_{s=0}^{\infty} \zeta_{w}^{s} \beta^{s}\left[\left(X_{t, s}^{W} W_{t}^{r e l} \frac{\tilde{W}_{t}}{\tilde{W}_{t+s}}\right)^{-\frac{1+\lambda_{w}}{\lambda_{w}}} H_{t+s}\right] \lambda_{t+s}^{I} \times \\
\left\{\left(1+\lambda_{w}\right)\left(X_{t, s}^{W} W_{t}^{r e l} \frac{\tilde{W}_{t}}{\tilde{W}_{t+s}}\right)^{-\frac{\left(1+\lambda_{w}\right) \varphi}{\lambda_{w}}} \frac{H_{t+s}^{\varphi}}{\lambda_{t+s}^{I}}-X_{t, s}^{W} W_{t}^{r e l} \tilde{W}_{t}\right\}=0
\end{gathered}
$$

where $X_{t, s}^{W} \equiv \frac{\prod_{l=1}^{s}(\pi)^{\left(1-i_{w}\right)}\left(\pi_{t+l-1}\right)^{i_{w}}}{\prod_{l=1}^{s} \pi_{t+l}}$ and $W_{t}^{r e l} \equiv \frac{\tilde{W}_{t}^{\text {new }}}{\tilde{W}_{t}}$ is the relative wage chosen by those households that are allowed to re-optimize their wage respect to the level of wages at time $t$. Wage evolution (17) expressed in term of relative wage became:

$$
\left(\tilde{W}_{t}\right)^{-\frac{1}{\lambda w}}=\left(1-\zeta_{w}\right)\left(W_{t}^{r e l} \tilde{W}_{t}\right)^{-\frac{1}{\lambda w}}+\zeta_{w}\left[\frac{(\pi)^{\left(1-i_{w}\right)}\left(\pi_{t-1}\right)^{i_{w}}}{\pi_{t}} \tilde{W}_{t-1}\right]^{-\frac{1}{\lambda_{w}}}
$$

\section{B.1.3 Firms.}

Firms' cost minimization problem yields the following demand for capital and labor inputs:

$$
\begin{gathered}
R_{t}=\alpha M C_{t} \frac{Y_{t}}{K_{t}} \\
W_{t}=M C_{t}(1-\alpha) \frac{Y_{t}}{H_{t}}
\end{gathered}
$$

where the $j$ index has been dropped because input prices are given for firms and hence inputs demand is the same across all firms. Combining the two equations above yields 
the input ratio (5). The ratio can also be expressed in real term:

$$
\frac{K_{t}}{H_{t}}=\frac{\alpha}{1-\alpha} \frac{\tilde{W}_{t}}{\tilde{R}_{t}}
$$

Combining (36) and (37) together with the production function (3) yields the expression for nominal marginal costs in (6). In real terms marginal costs are:

$$
\tilde{M} C_{t}=\frac{1}{\alpha^{\alpha}(1-\alpha)^{(1-\alpha)}} \frac{\tilde{W}_{t}^{(1-\alpha)} \tilde{R}_{t}^{\alpha}}{X_{t}^{(1-\alpha)}}
$$

\section{B.1.4 Price setting.}

Firms first order condition for the optimal price setting problem in (7) is:

$$
\mathbb{E}_{t} \sum_{s=0}^{\infty}\left(\zeta_{p} \beta\right)^{s}\left(\frac{\lambda_{t+s}}{\lambda_{t}}\right)\left(X_{t, s}\right)^{-\frac{1+\lambda_{f}}{\lambda_{f}}}\left\{\left[\left(1+\lambda_{f}\right) \tilde{M} C_{t+s}-P_{t}^{r e l}\left(X_{t, s}\right)\right]\right\}=0
$$

where $X_{t, s}=\frac{1}{s}$ and the relative price $P_{t}^{r e l}$ is defined as $P_{t}^{\text {rel }} \equiv \frac{P_{t}^{\text {new }}}{P_{t}}$, where $P_{t}^{\text {new }}$ is $\prod_{l=1} \pi_{t+l}$

the new price chosen by those firms able to re-optimize their price.

Price evolution (8) can be rewritten in terms of relative price as:

$$
\left(1-\zeta_{p}\right)\left(P_{t}^{r e l}\right)^{-\frac{1}{\lambda_{f}}}+\zeta_{p}\left(\frac{1}{\pi_{t}}\right)^{-\frac{1}{\lambda_{f}}}=1
$$

Equation (40) and (41) can be combined to obtain the new-Keynesian Phillips curve.

\section{B.2 Equilibrium equations}

The model equilibrium is defined by equations (29), (30), (31), (32), (33), (34), (35), (38), (39), (40), (41), plus the production function (3), the LBD accumulation process (4), the capital accumulation process (13), the monetary policy rule (19), the definition of GDP (18), the government spending process evolution (20), the goods market clearing condition (22) and the definition of effective capital discussed in the main text. 


\section{B.3 Steady states}

Steady states values in term of fixed parameters are:

$$
\begin{gathered}
M C=\frac{1}{1+\lambda_{f}} \\
R=\frac{1}{\beta}-(1-\delta) \\
\frac{K}{Y}=\alpha \frac{M C}{R} \\
\frac{F}{Y}=\delta \frac{K}{Y} \\
\frac{C}{Y}=1-\frac{F}{Y}-\frac{G}{Y}
\end{gathered}
$$

\section{B.4 Log-linearized model}

Let lower-case variables with “^” denoting variables in log-deviation from steady states and where appropriate expressed in real term, the log-linearized equilibrium conditions around steady-states levels are given by:

$$
\begin{gathered}
\widehat{\lambda}_{t}^{I}=\mathbb{E}_{t}\left[\widehat{\lambda}_{t+1}^{I}\right]+\hat{i}_{t}-\mathbb{E}_{t}\left[\hat{\pi}_{t+1}\right] \\
(1-\gamma \beta)(1-\gamma) \widehat{\lambda}_{t}^{I}=-\left(1+\gamma^{2} \beta\right) \widehat{c}_{t}+\gamma \widehat{c}_{t-1}+\gamma \beta \mathbb{E}_{t}\left[\widehat{c}_{t+1}\right] \\
(1+\beta) \widehat{f}_{t}=\widehat{f}_{t-1}+\beta \mathbb{E}_{t}\left[\widehat{f}_{t+1}\right]+\frac{\left(\widehat{\lambda}_{t}^{K}-\widehat{\lambda}_{t}^{I}\right)}{S^{\prime \prime}(1)}
\end{gathered}
$$




$$
\begin{aligned}
\widehat{\lambda}_{t}^{K}-\widehat{\lambda}_{t}^{I}= & {[1-\beta(1-\delta)] \mathbb{E}_{t}\left[\widehat{r}_{t+1}\right]+\beta(1-\delta) \mathbb{E}_{t}\left[\widehat{\lambda}_{t+1}^{K}-\widehat{\lambda}_{t+1}^{I}\right] } \\
& -\left(\hat{i}_{t}-\mathbb{E}_{t}\left[\hat{\pi}_{t+1}\right]\right)
\end{aligned}
$$

$$
R \widehat{r}_{t}=a^{\prime \prime}(u) \widehat{u}_{t}
$$

$$
\begin{aligned}
& \widehat{w}_{t}^{r e l}=\zeta_{w} \beta\left\{\mathbb{E}_{t}\left[\widehat{w}_{t+1}^{r e l}\right]+\mathbb{E}_{t}\left[\widehat{w}_{t+1}\right]-\widehat{w}_{t}-i_{w} \widehat{\pi}_{t}+\mathbb{E}_{t}\left[\widehat{\pi}_{t+1}\right]\right\} \\
& +\frac{\lambda_{w}\left(1-\zeta_{w} \beta\right)}{\lambda_{w}+\left(1+\lambda_{w}\right) \varphi}\left\{\varphi \widehat{h}_{t}-\widehat{\lambda}_{t}^{I}-\widehat{w}_{t}\right\} \\
& \widehat{w}_{t}=i_{w} \widehat{\pi}_{t-1}-\widehat{\pi}_{t}+\widehat{w}_{t-1}+\frac{\left(1-\zeta_{w}\right)}{\zeta_{w}} \widehat{w}_{t}^{r e l} \\
& \widehat{r}_{t}+\widehat{k}_{t}=\widehat{h}_{t}+\widehat{w}_{t} \\
& \widehat{m c}_{t}=(1-\alpha)\left(\widehat{w}_{t}-\widehat{x}_{t}\right)+\alpha \widehat{r}_{t} \\
& \widehat{\pi}_{t}=\beta \mathbb{E}_{t}\left[\widehat{\pi}_{t+1}\right]+\frac{\left(1-\zeta_{p} \beta\right)\left(1-\zeta_{p}\right)}{\zeta_{p}} \widehat{m c}_{t} \\
& \widehat{y}_{t}=(1-\alpha)\left(\widehat{x}_{t}+\widehat{h}_{t}\right)+\alpha \widehat{k}_{t} \\
& \widehat{x}_{t}=\rho_{x} \widehat{x}_{t-1}+\mu_{n} \widehat{h}_{t-1} \\
& \widehat{\bar{k}}_{t}=(1-\delta) \widehat{\bar{k}}_{t-1}+\widehat{\delta}_{t} \\
& \widehat{i}_{t}=\rho_{r} \widehat{i}_{t-1}+\left(1-\rho_{r}\right)\left[\phi_{\pi} \mathbb{E} \widehat{\pi}_{t+1}+\frac{\phi_{\Delta y}}{4}\left(g \widehat{d p_{t}}-g \widehat{d p}_{t-1}\right)\right] \\
& g \widehat{d p}_{t}=\frac{C}{Y} \widehat{c}_{t}+\frac{F}{Y} \widehat{f}_{t}+\frac{G}{Y} \widehat{g}_{t} \\
& \widehat{g}_{t}=\rho_{g} \widehat{g}_{t-1}+\varepsilon_{t}^{g} \\
& \widehat{y}_{t}=\frac{C}{Y} \widehat{c}_{t}+\frac{F}{Y} \widehat{f}_{t}+R \frac{K}{Y} \widehat{u}_{t}+\frac{G}{Y} \widehat{g}_{t} \\
& \widehat{k}_{t}=\widehat{u}_{t}+\widehat{\bar{k}}_{t-1}
\end{aligned}
$$




\section{LBD and indeterminacy}

The introduction of LBD impacts on the ability of the monetary authority to control inflation expectations and, by implementing a Taylor rule, to bring about a unique and stable equilibrium. In fact, the traditional wisdom, summarized by the Taylor rule, requires that for any 1 per cent variation in inflation, central bankers should change nominal interest rate by more than 1 per cent. However, in a model with LBD the Taylor rule no longer assures the model stability and, on the contrary, can lead to the unstable solutions represented by the white area in fig. 10. To see this point, consider the simplified model presented in section 4 in the main text. Without loss of generality we also assume that government is absent and there are no wage frictions. We also assume that monetary authority targets expected inflation. This kind of model can be summarized by the following system of equations:

$$
\begin{gathered}
\widehat{y}_{t}=\widehat{h}_{t}+\widehat{x}_{t} \\
\widehat{y}_{t}=\widehat{c}_{t} \\
\widehat{h}_{t}+\widehat{c}_{t}=\widehat{w}_{t} \\
\widehat{i}_{t}=\phi_{\pi} \mathbb{E}_{t}\left[\widehat{\pi}_{t+1}\right]
\end{gathered}
$$

where equation (65) is the production function, equation (66) is the market clearing condition, (67) states that the marginal rate of substitution between consumption and leisure must be equal to real wage and (68) is a Taylor rule targeting expected inflation. Equations (23)-(27) complete the model description. From (26) inflation can be stabilized controlling for the level of marginal costs. Plugging (67) into (27) and combing (65) and (66) marginal costs can be rewritten as: 


$$
\widehat{m c}_{t}=2\left(\widehat{c}_{t}-\widehat{x}_{t}\right)
$$

Using equation (25), equation (69) becomes:

$$
\widehat{m c}_{t}=-2 \mathbb{E}_{t} \sum_{s=0}^{\infty}\left(\widehat{i}_{t+s}-\widehat{\pi}_{t+1+s}\right)-2 \widehat{x}_{t}
$$

Finally, plugging the monetary rule 68 into equation (70) yields:

$$
\widehat{m c}_{t}=-2 \mathbb{E}_{t} \sum_{s=0}^{\infty}\left(\phi_{\pi}-1\right) \widehat{\pi}_{t+1+s}-2 \widehat{x}_{t}
$$

To see how the Taylor principle works, first consider a model without LBD, so that the last term in the equation (71) disappears. Suppose the economy is hit by a shock that increases marginal costs and inflation. In the attempt to stabilize inflation, the central bank raises the nominal interest rate. If $\phi_{\pi}>1$ it means that nominal interest rate increase more than inflation. Hence, as far as inflation is above steady state, marginal costs decline (see (71) ). In fact an increase in the real interest rate, by the Euler equation described in (25), and considering the market clearing condition described in the equation (66) leads to a reduction in the output, which in turn brings a reduction in the marginal costs and hence, by equation (26), in the level of inflation. Thus, the economy reverts to the steady state level. Now consider the case with LBD. As in the previous example the economy is hit by a shock that increase inflation and the monetary authority reacts by increasing the interest rate. However, the LBD mechanism adds a new element to the story described above. A reduction in the output, leads to fall in the hours worked and, by the LBD process, to a decrease in the level of stock of knowledge and hence, as described in equation (71) to a pressure on the level of marginal costs. If the LBD mechanism is strong enough, the increase in the nominal interest rate leads to an increase in the level of inflation. In this case, inflation expectation become self-fulfilling. Central banker is no longer able to control inflation expectation and hence the economy fluctuates between booms a recessions. 


\section{Data sources}

This section describes more in details the data employed in the estimation of the VAR models.

Total Factor Productivity: Utilization-adjusted, quarterly TFP series for the U.S. Business Sector, produced by John Fernald. Source: Federal Reserve Bank of San Francisco.

Government spending: Government Consumption expenditures + Gross government investment - Consumption of fixed capital, Table 3.1 lines 21, 39 and 42. Source: Bureau of Economic Analysis (BEA); Note: Seasonally adjusted at annual rates.

GDP: Gross Domestic Product, Table 1.1.5 line 1. Source : Bureau of Economic Analysis (BEA); Note: Seasonally adjusted at annual rates. Analysis (BEA). Note: Seasonally adjusted at annual rates.

Consumption: Non-durable goods +services, Table 1.1.5 lines 5 and 6. Source: Bureau of Economic Analysis (BEA); Note: Seasonally adjusted at annual rates.

Investment: Gross private domestic investment + Personal consumption expenditures of durable goods, Table 1.1.5 lines 7 and 4. Source: Bureau of Economic Analysis (BEA); Note: Seasonally adjusted at annual rates.

Real Wage: Nominal wage deflated by GDP deflator. Nominal wage: Compensation Per Hour (COMPNFB) in the Non-farm Business Sector. Source: U.S. Bureau of Labor Statistics, Productivity and Costs. Note: Seasonally Adjusted, Quarterly, Index numbers $2009=100$.

Total Government Receipts: Current receipts - Current transfer payments - Interest payments, Table 3.1 lines 1, 22 and 27. Source: Bureau of Economic Analysis (BEA); Note: Seasonally adjusted at annual rates. 
Hours: Employment×Average Weekly Hours. Employment: Civilian employment level (CE16OV). Source: FRED, Federal Reserve Bank of St. Louis. Note: Seasonally Adjusted, Quarterly, thousands. Average Weekly Hours: Nonfarm Business Sector: Average Weekly Hours (PRS85006023). Source: FRED, Federal Reserve Bank of St. Louis. Note: Seasonally Adjusted, Quarterly, Index numbers 2009=100.

Interest rate: Effective Federal Funds Rate (DFF). Source: FRED, Federal Reserve Bank of ST. Louise. Note: average of monthly figures. Not Seasonally Adjusted.

Inflation: Log differences of the Implicit Price Deflator for Gross Domestic Product, Table 1.1.9. line 1. Source: Bureau of Economic Analysis (BEA); Note: Index numbers, $2009=100$. Seasonally adjusted.

Shocks news: For the definition of shock news see Auerbach and Gorodnichenko (2012)

CPI Inflation: Log differences of Consumer Price Index for All Urban Consumers: All Items [CPIAUCSL], Source: U.S. Bureau of Labor Statistics.

Commodity Price: Log of Producer Price Index for All Commodities [PPIACO]. Source: U.S. Bureau of Labor Statistics.

All quantity variables are expressed as logs of real per capita amounts. 

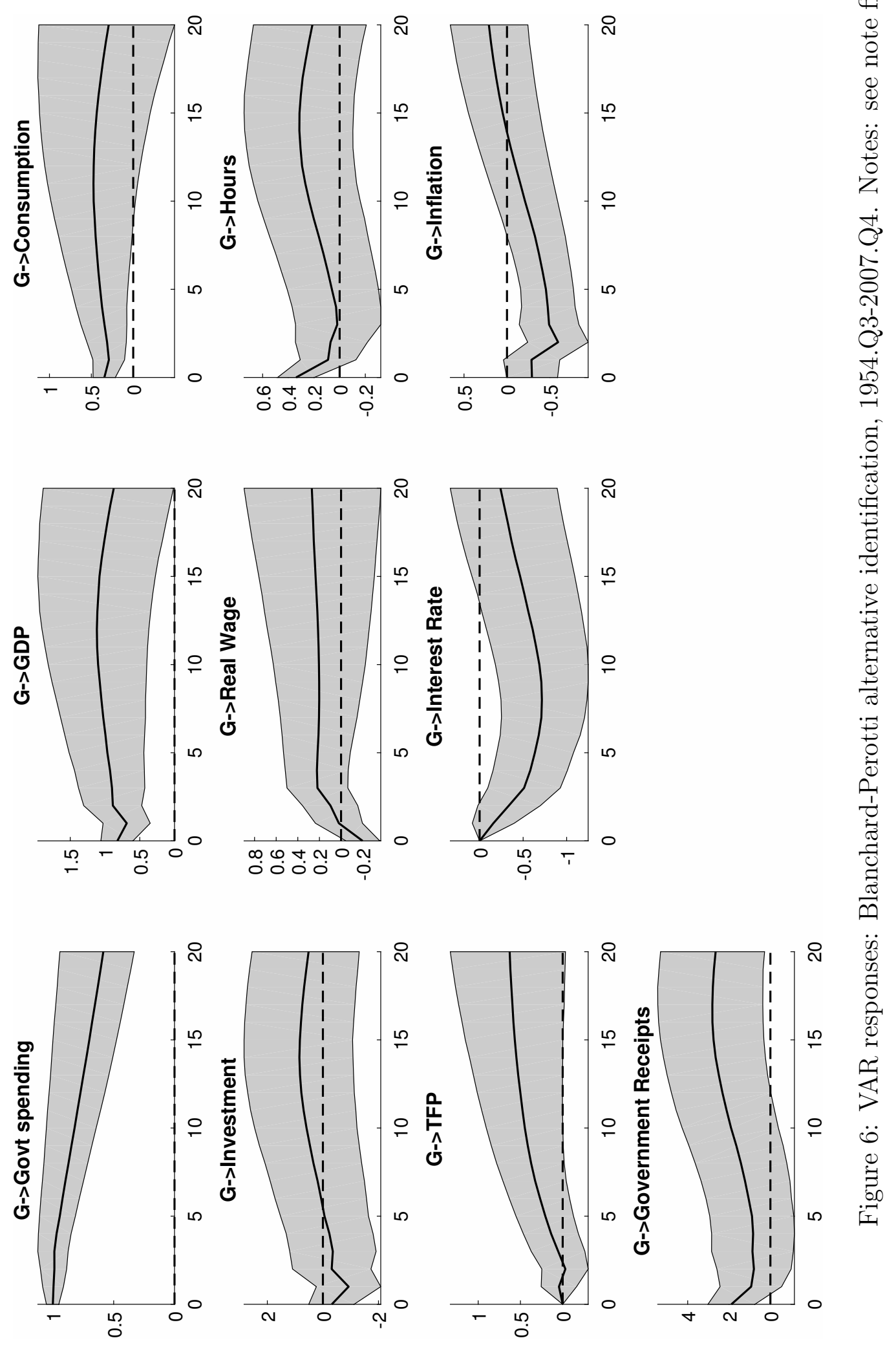


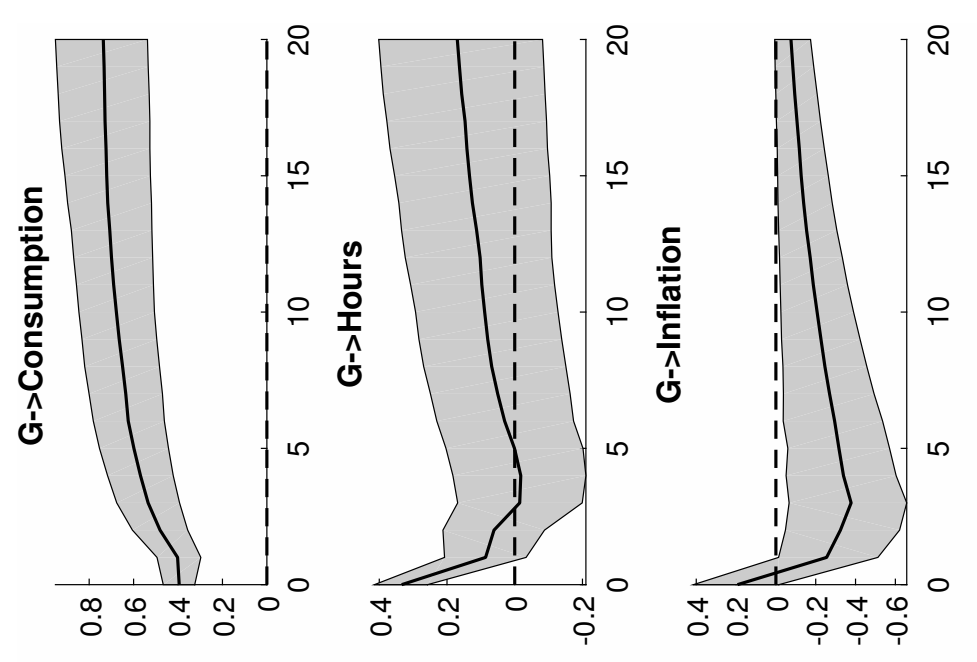

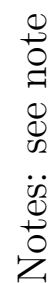

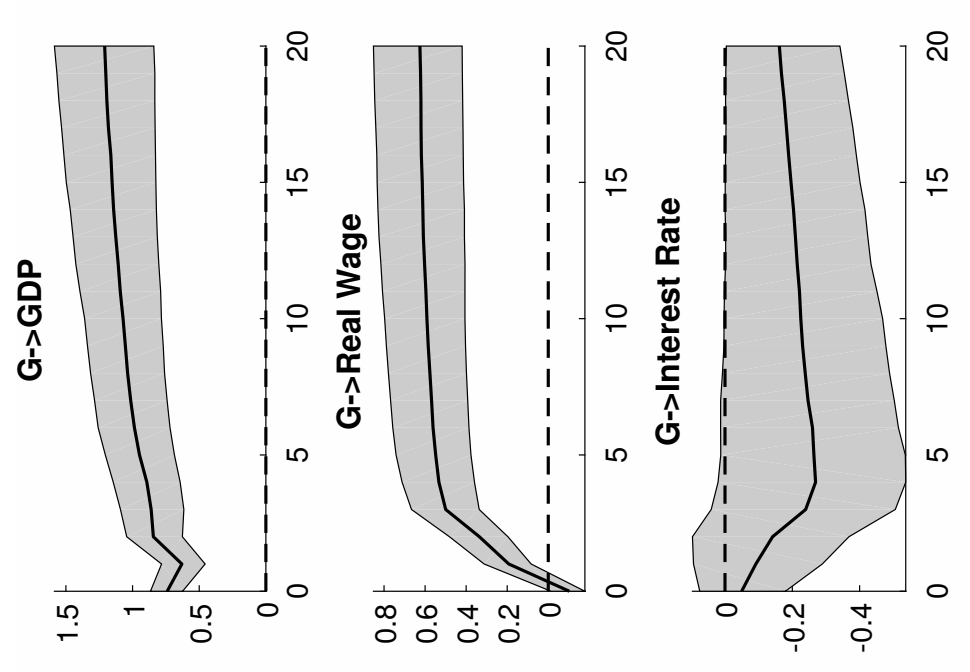

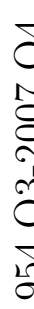

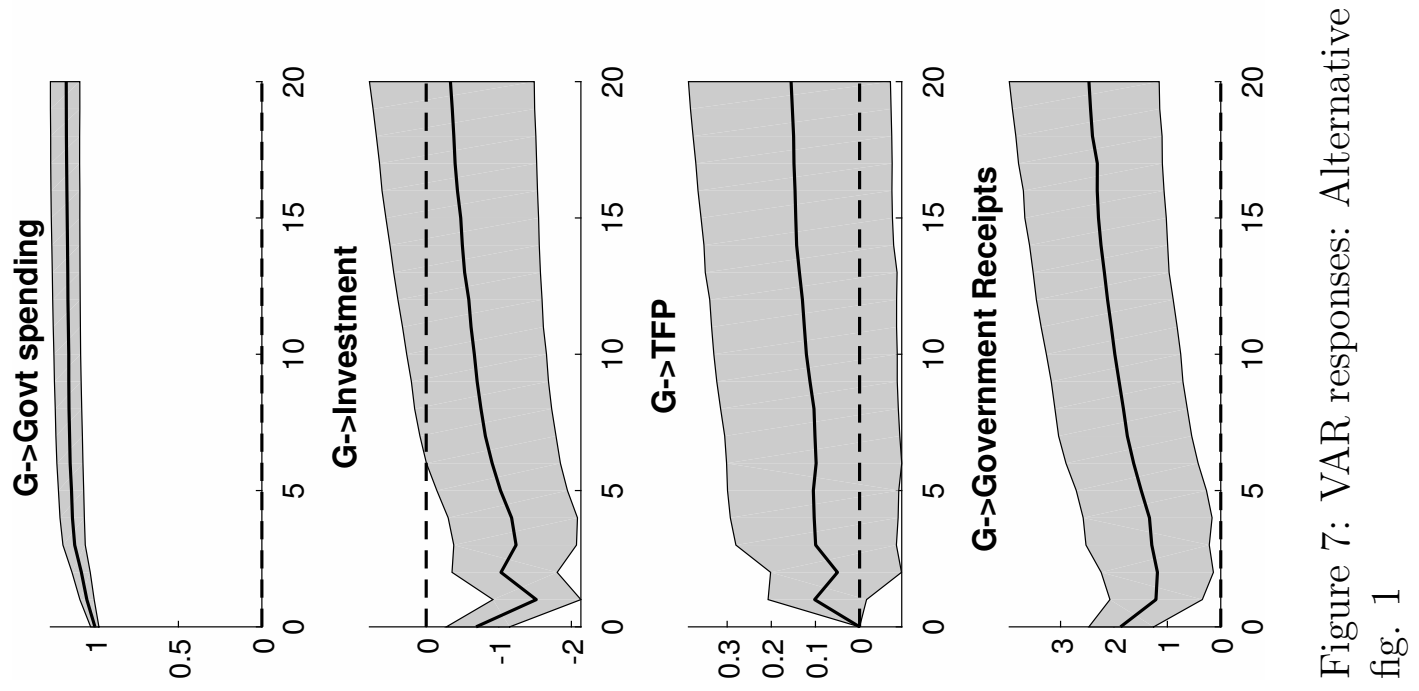



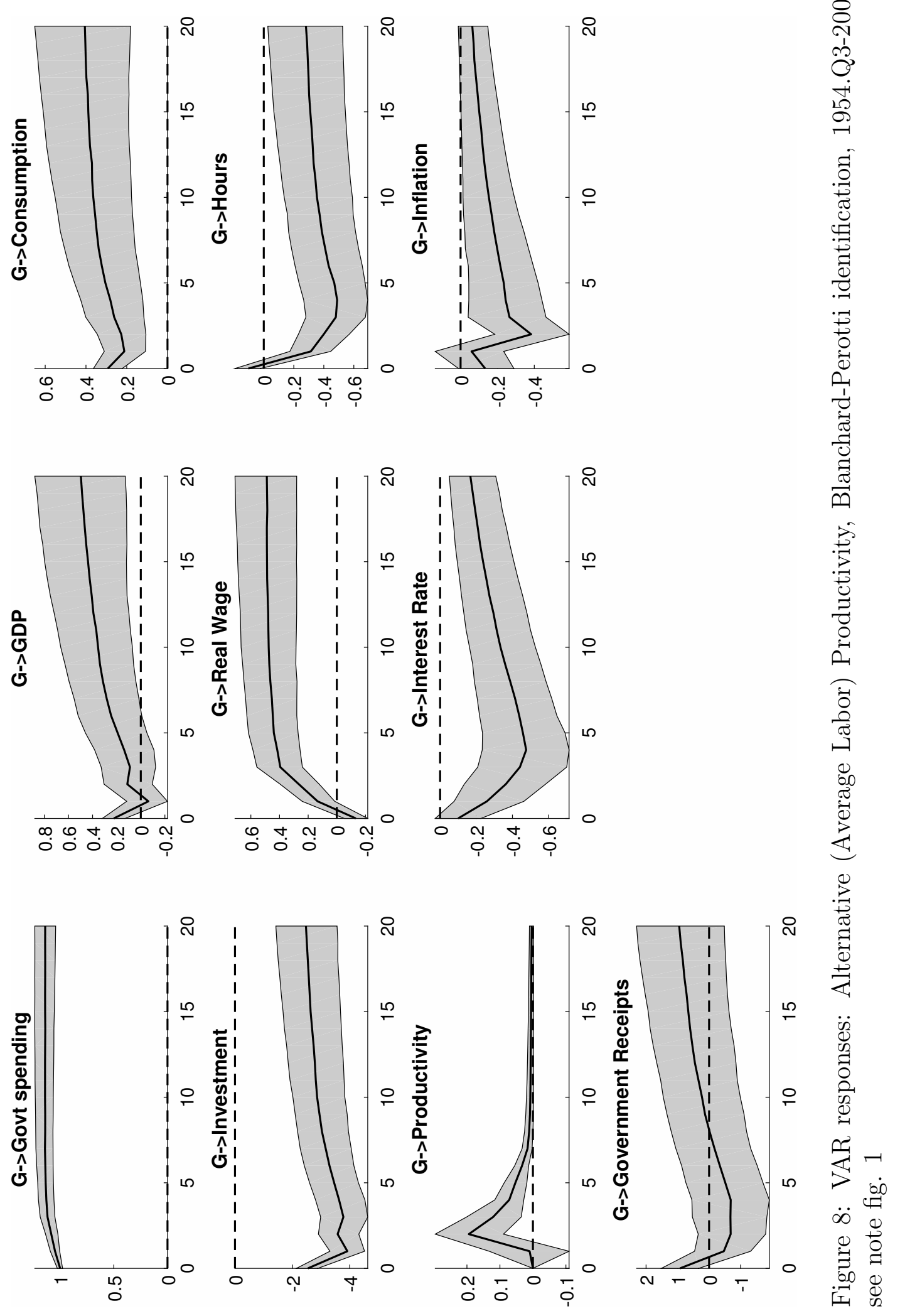


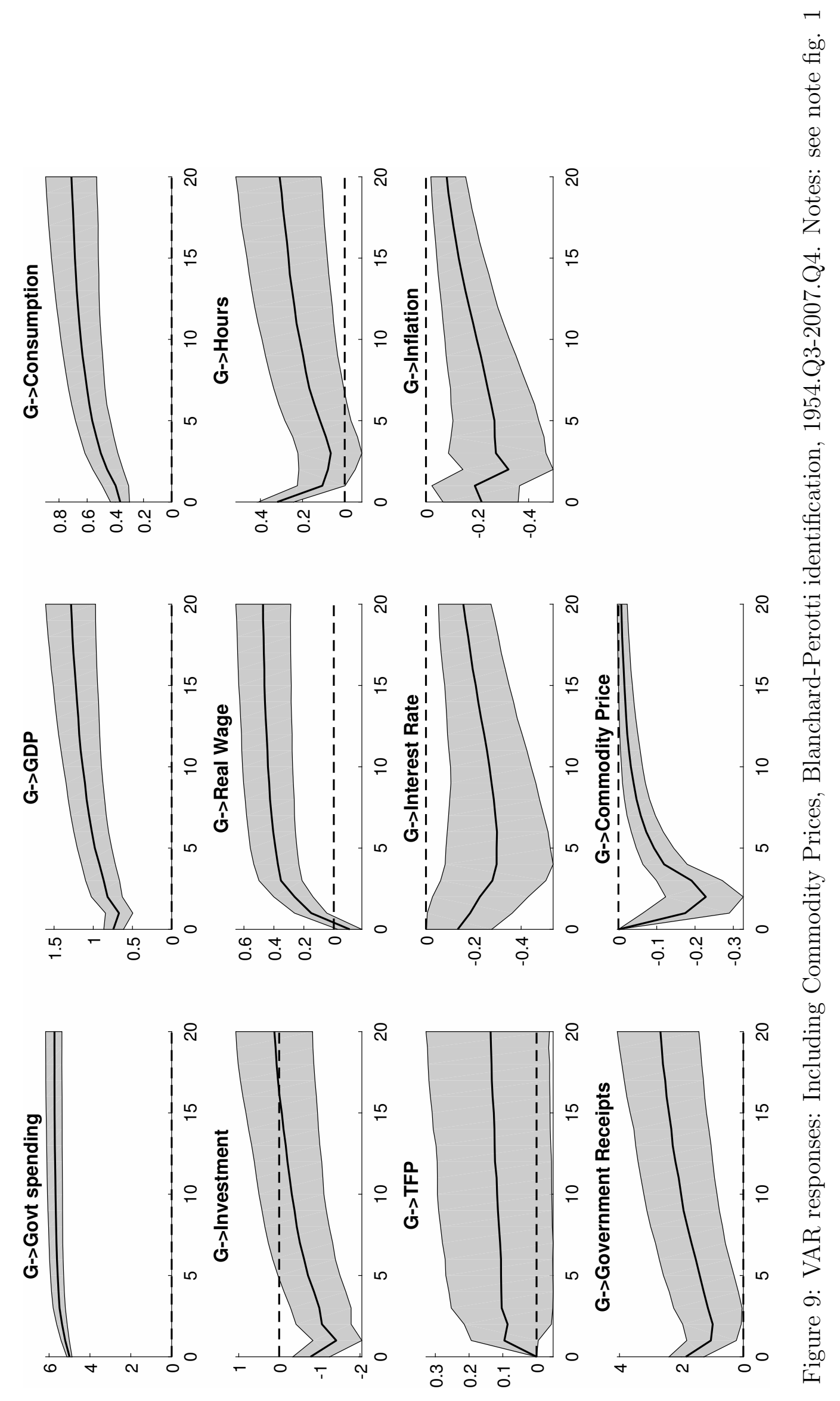




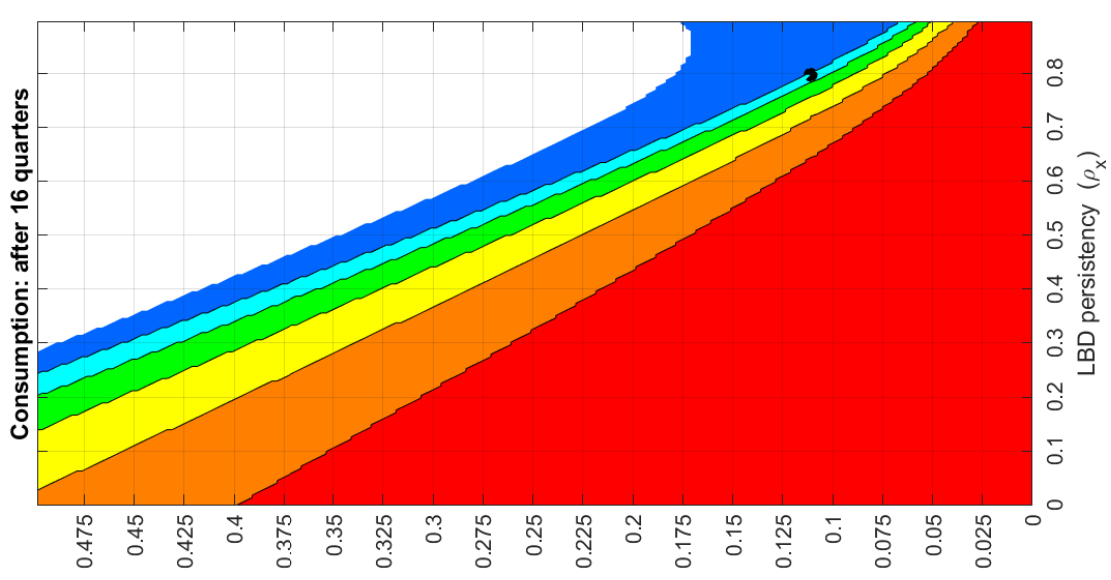

$\left({ }^{4}{ }^{\prime \prime}\right)$ ફvedu! sınou agา

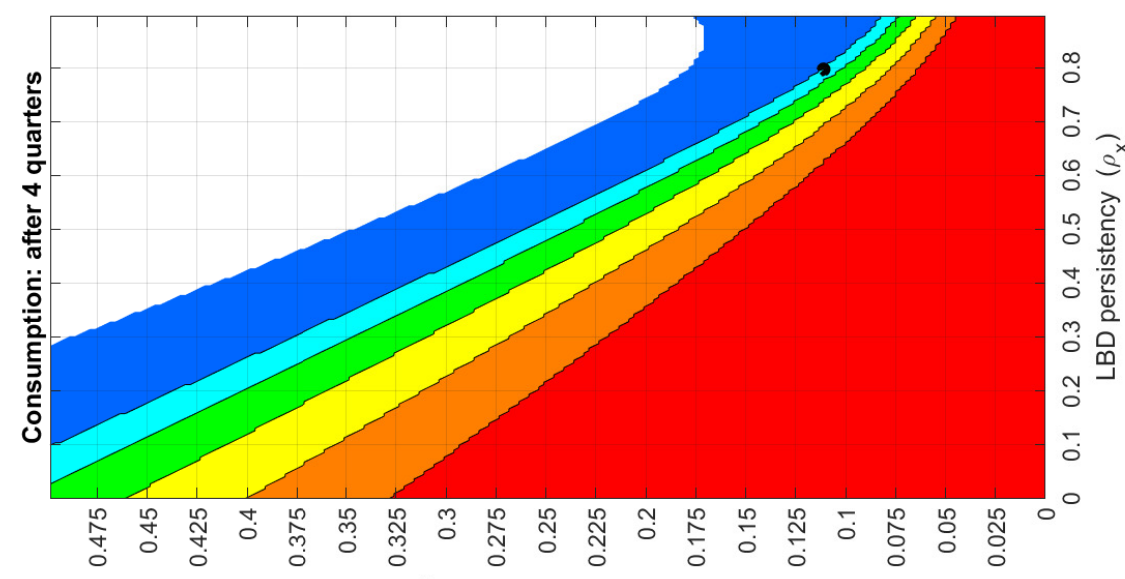

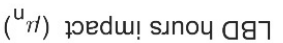

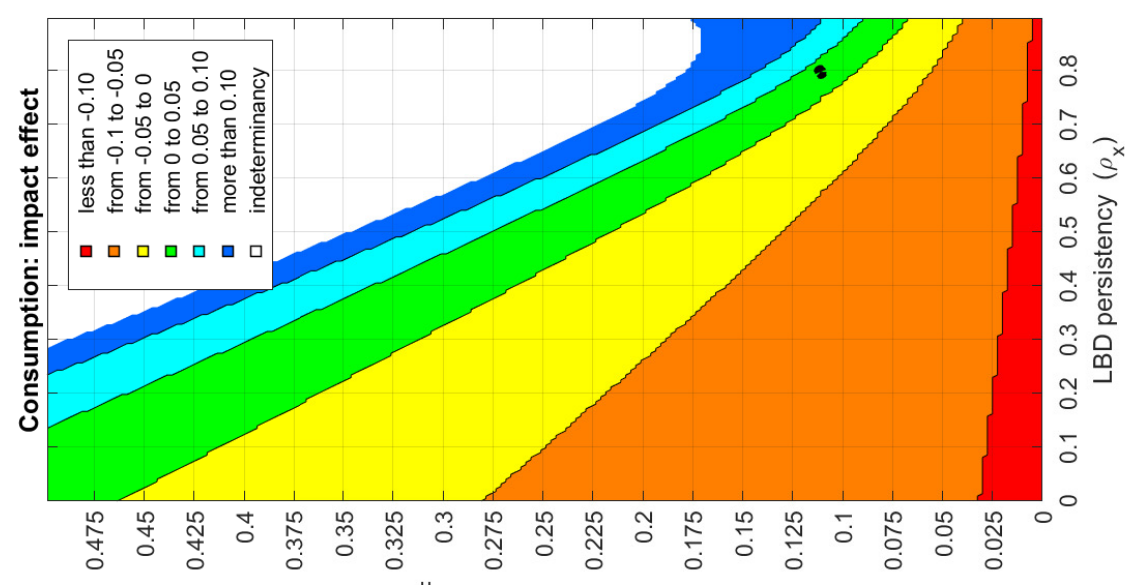

$\left({ }^{\mathrm{u}} r\right)$ łoedu! sınou 097 


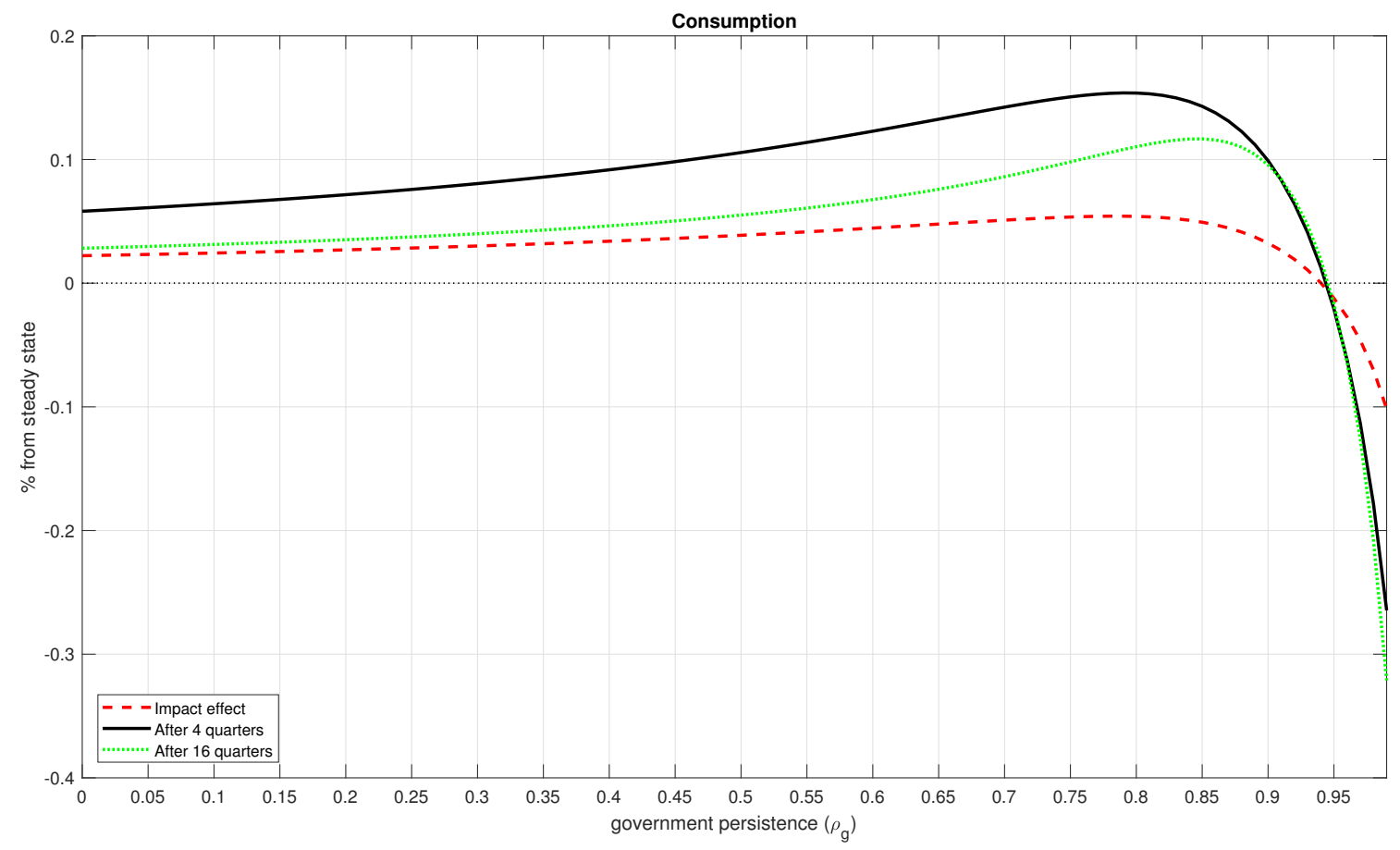

Figure 11: Impulse responses to a government spending shock: sensitivity to government spending persistence $\rho_{g}$. 

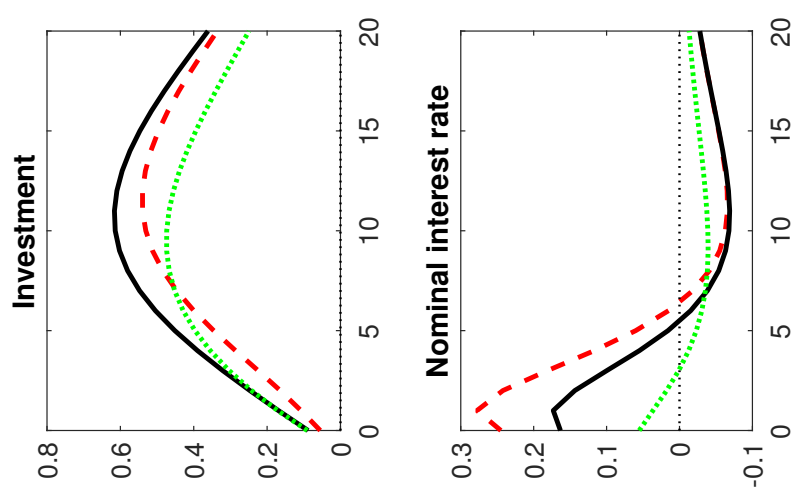

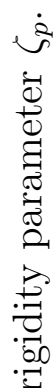
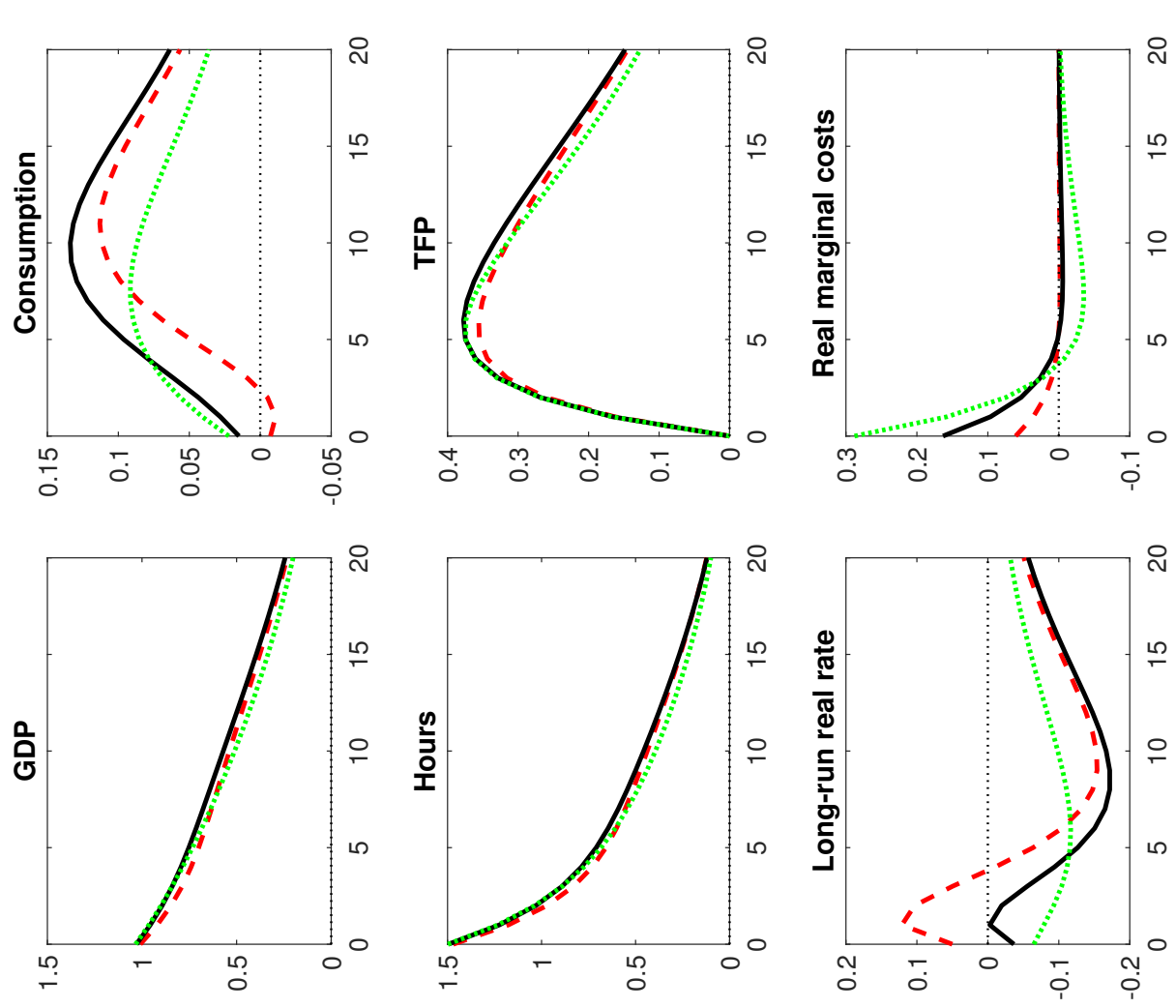

氙

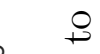

.

过
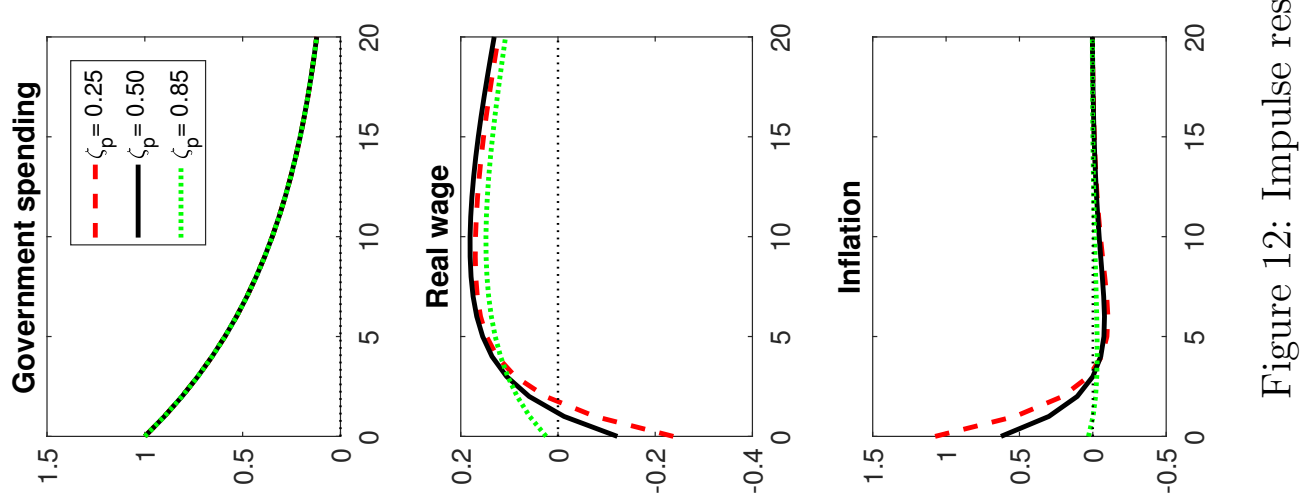

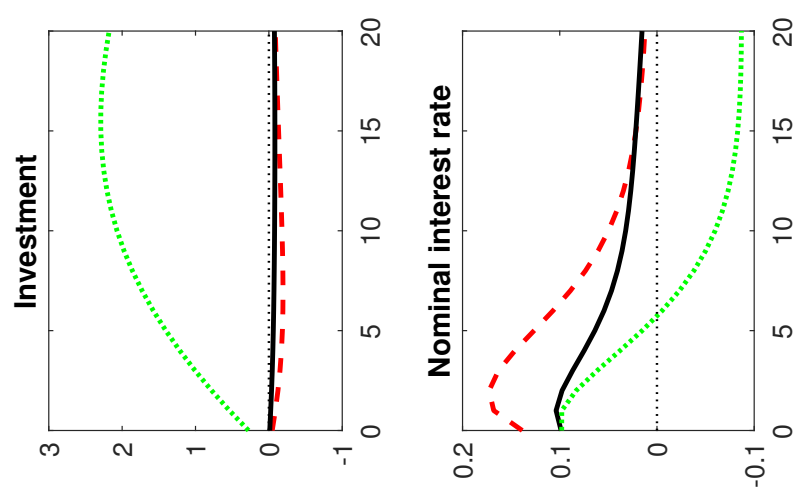

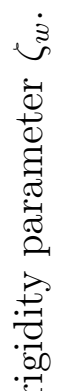
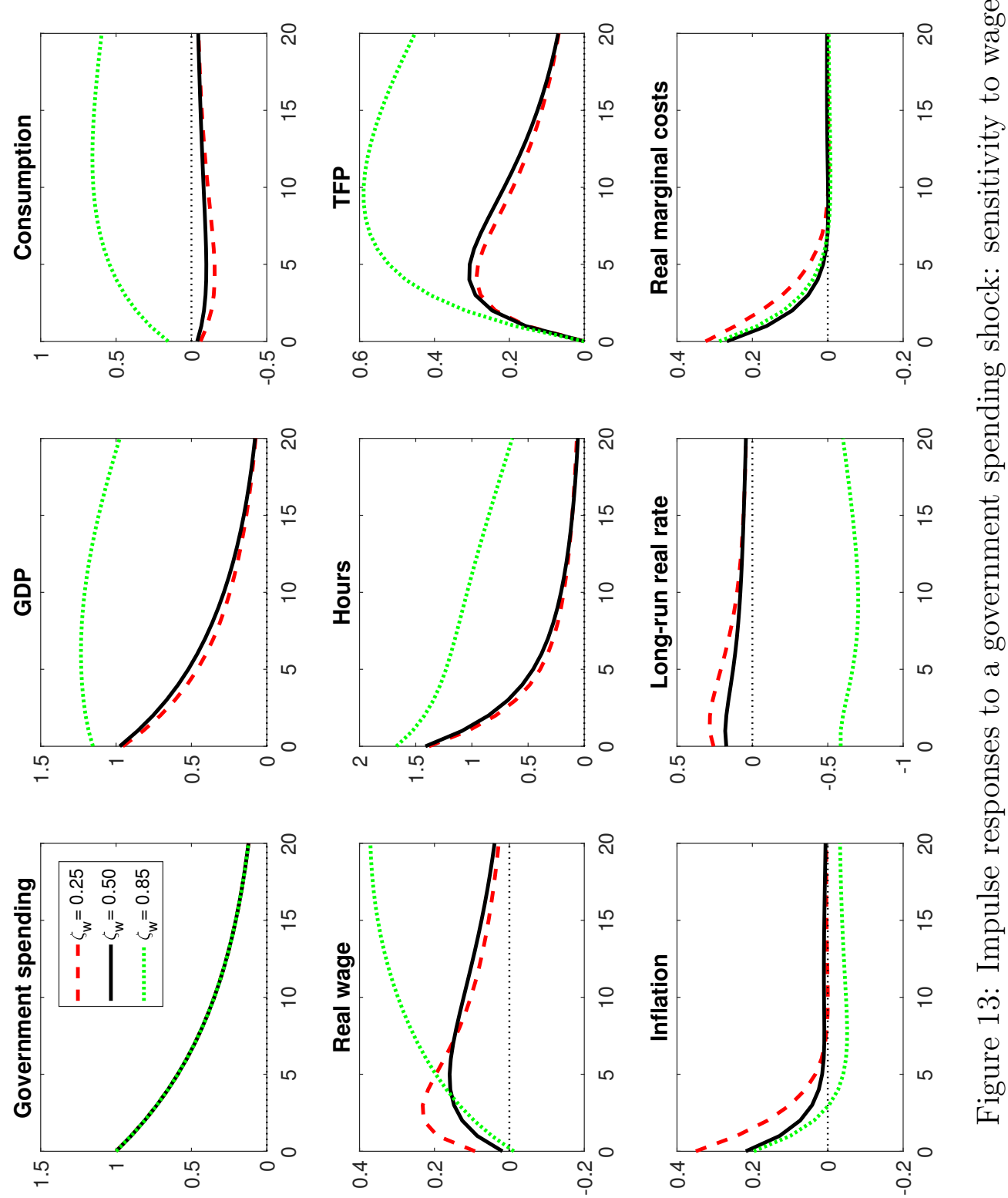

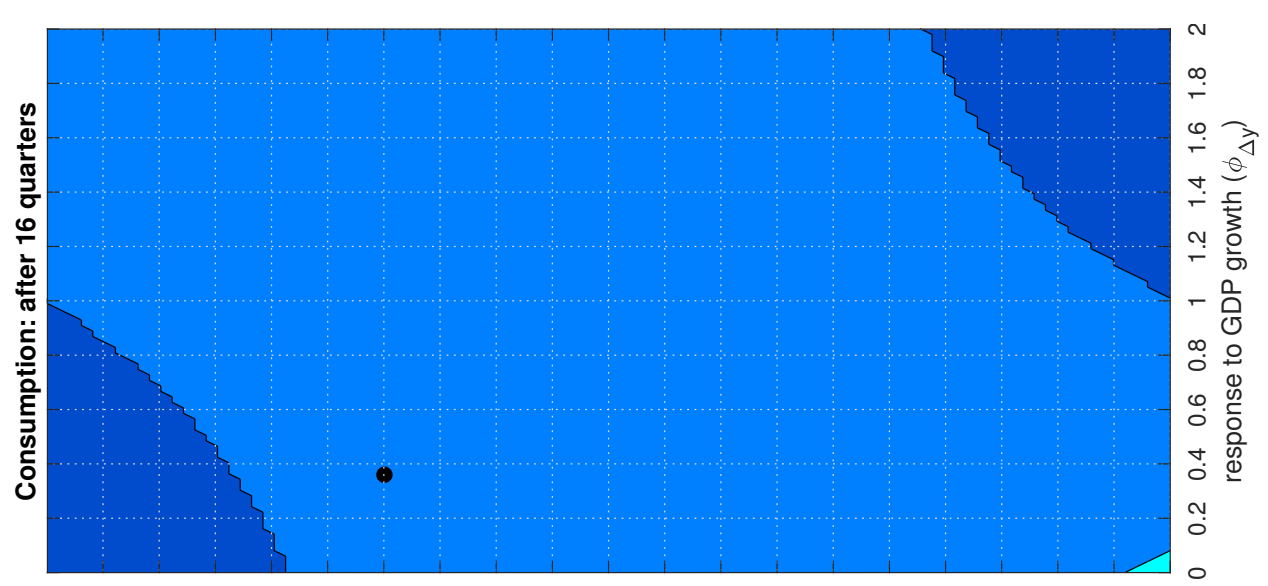

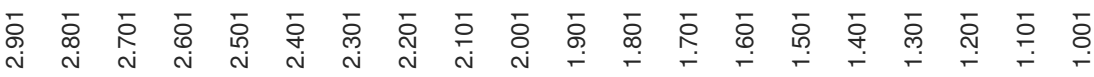

$\left({ }^{\Perp} \phi\right)$ uo!̣ı빈 아 әsuodsəג

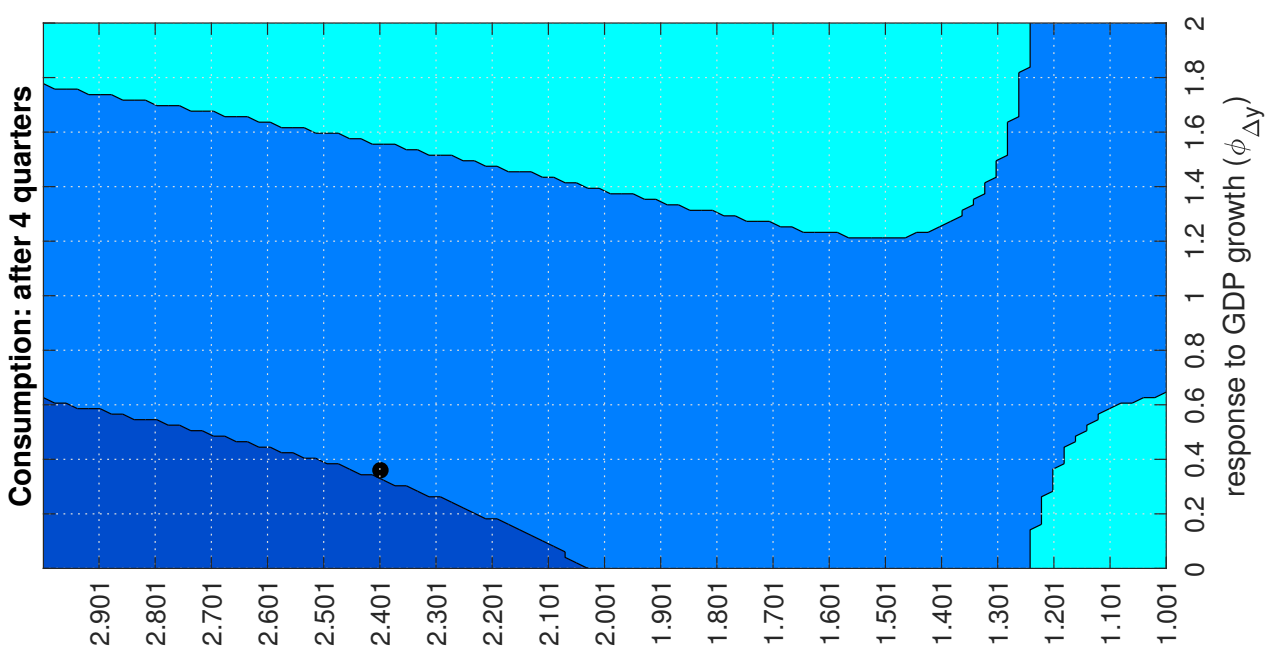

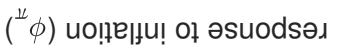

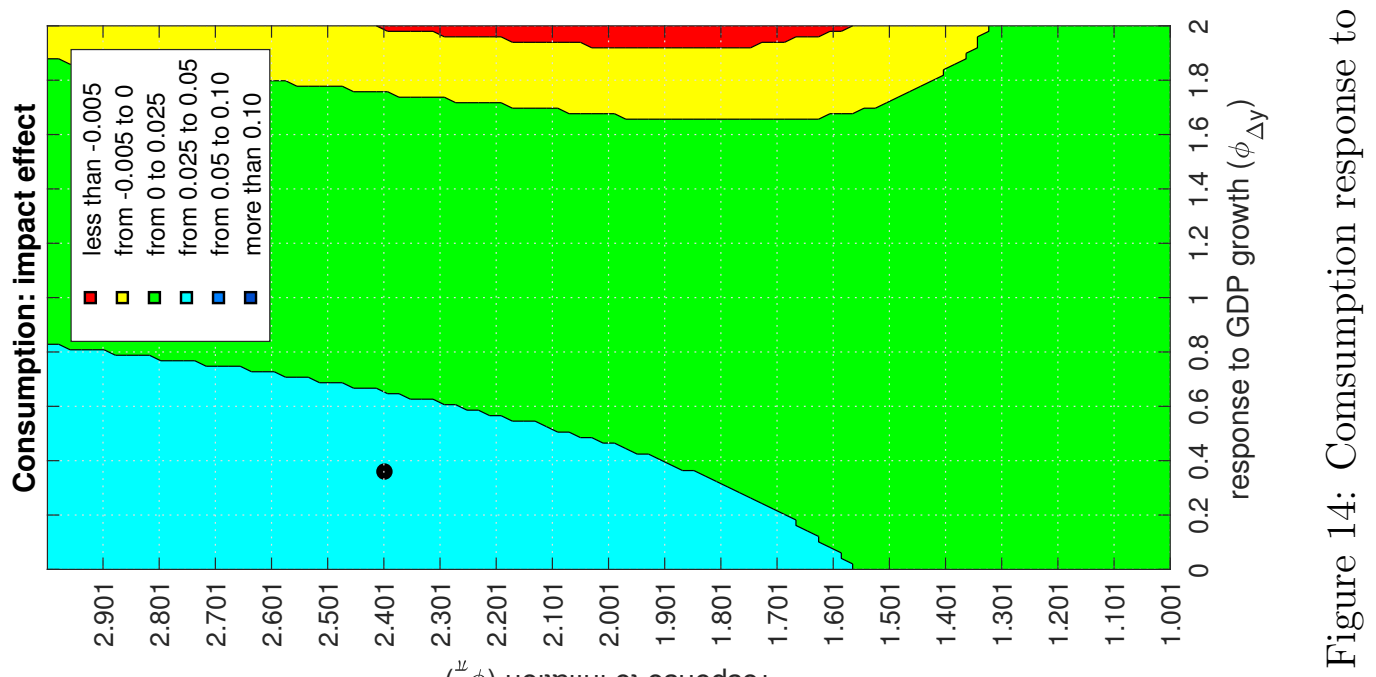

$\left({ }^{\Perp} \phi\right)$ uo!̣e|fu! 아 əsuodsəג 

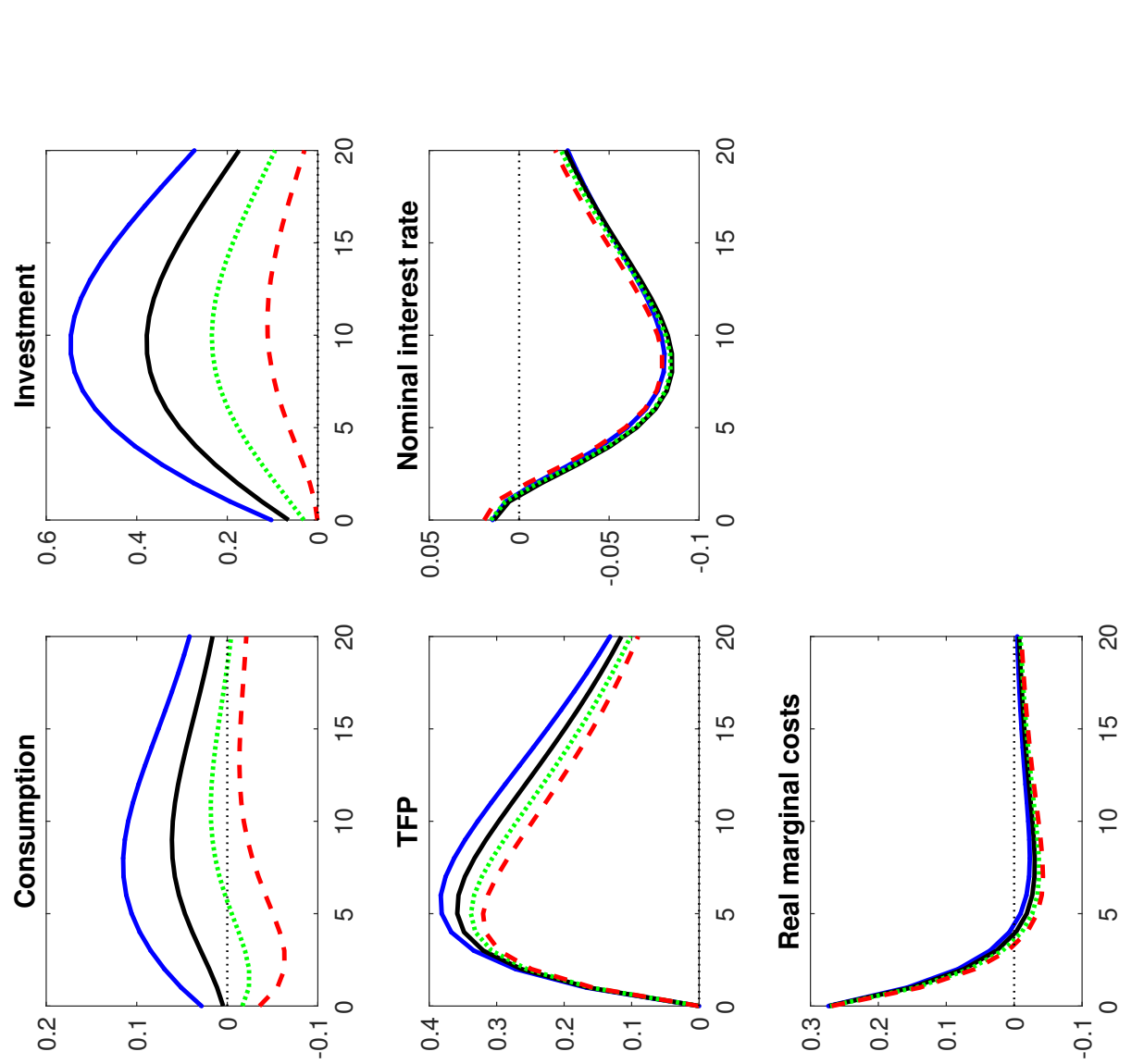

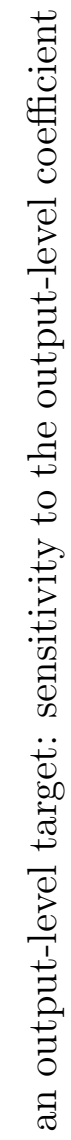
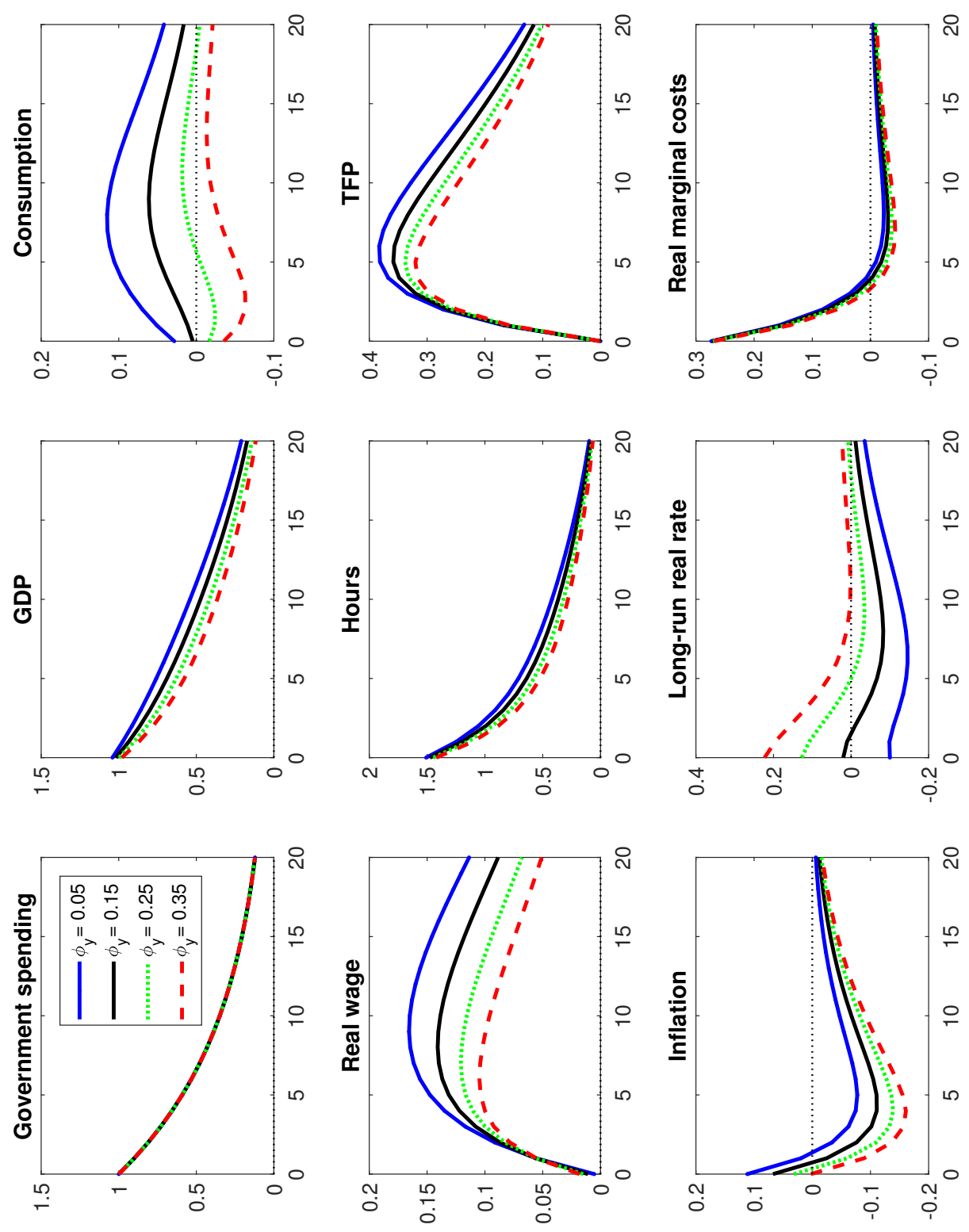

3
3
0
0
0
0
0
0
0
0
0
0
0
0
0 


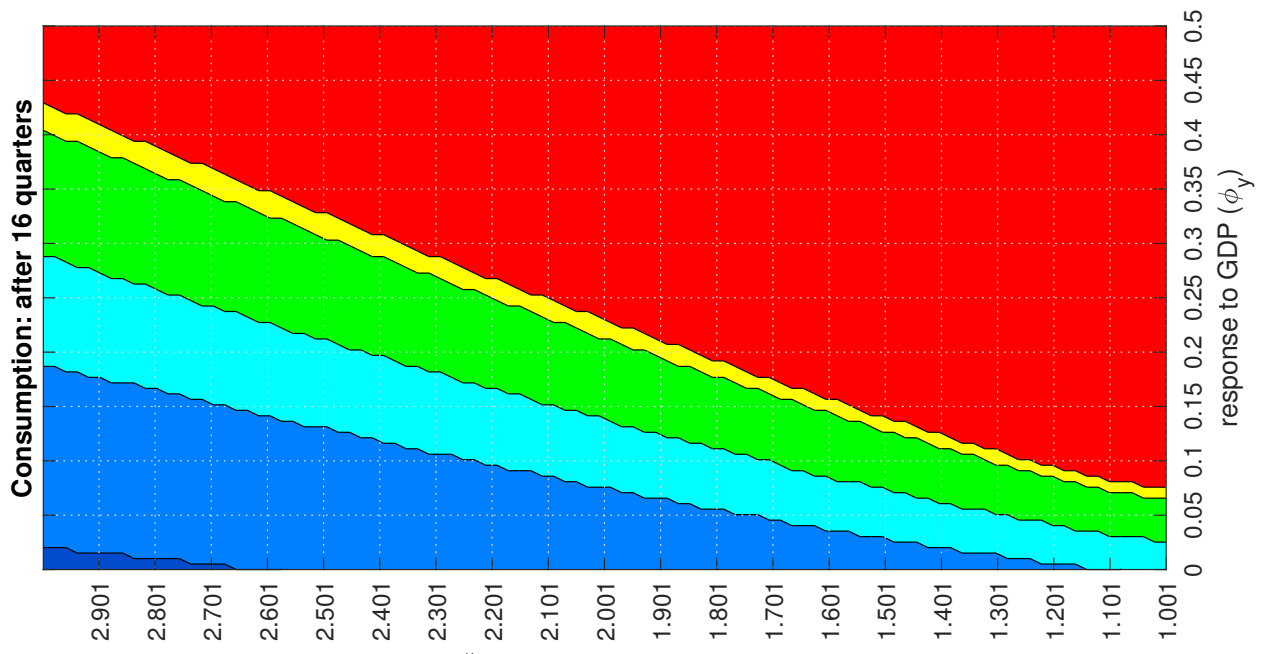

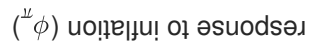

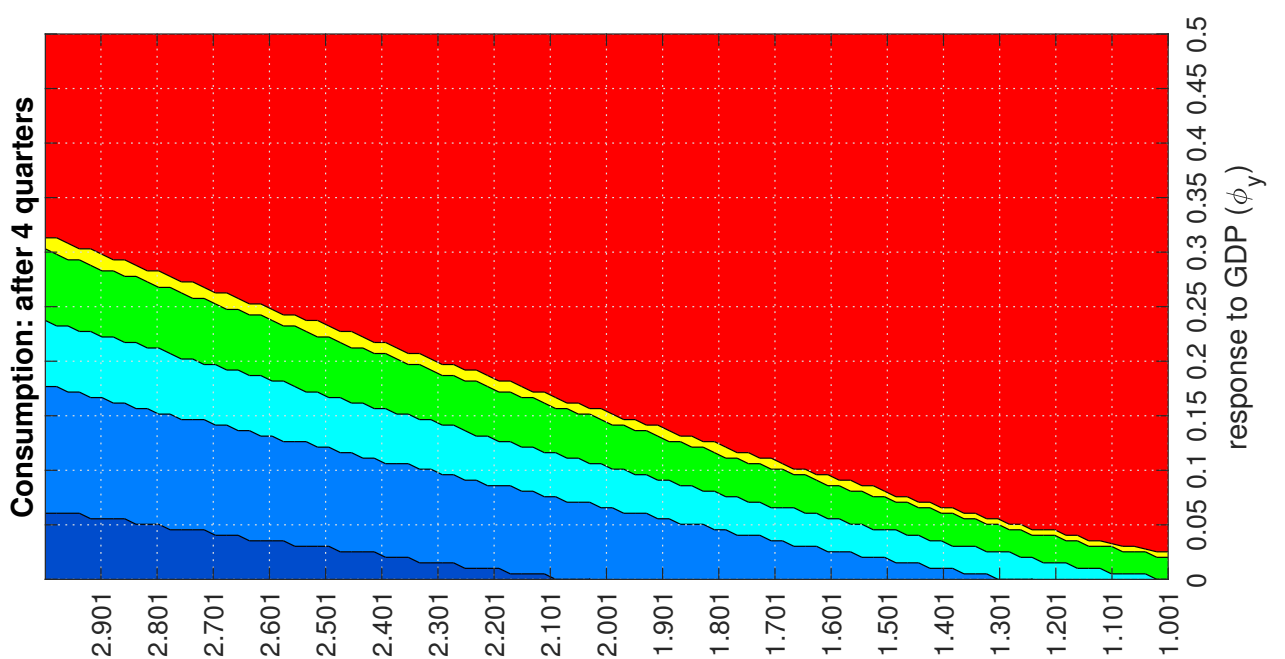

$\left({ }^{\Perp} \phi\right)$ uo!̣e|ıu! ol əsuodsəג

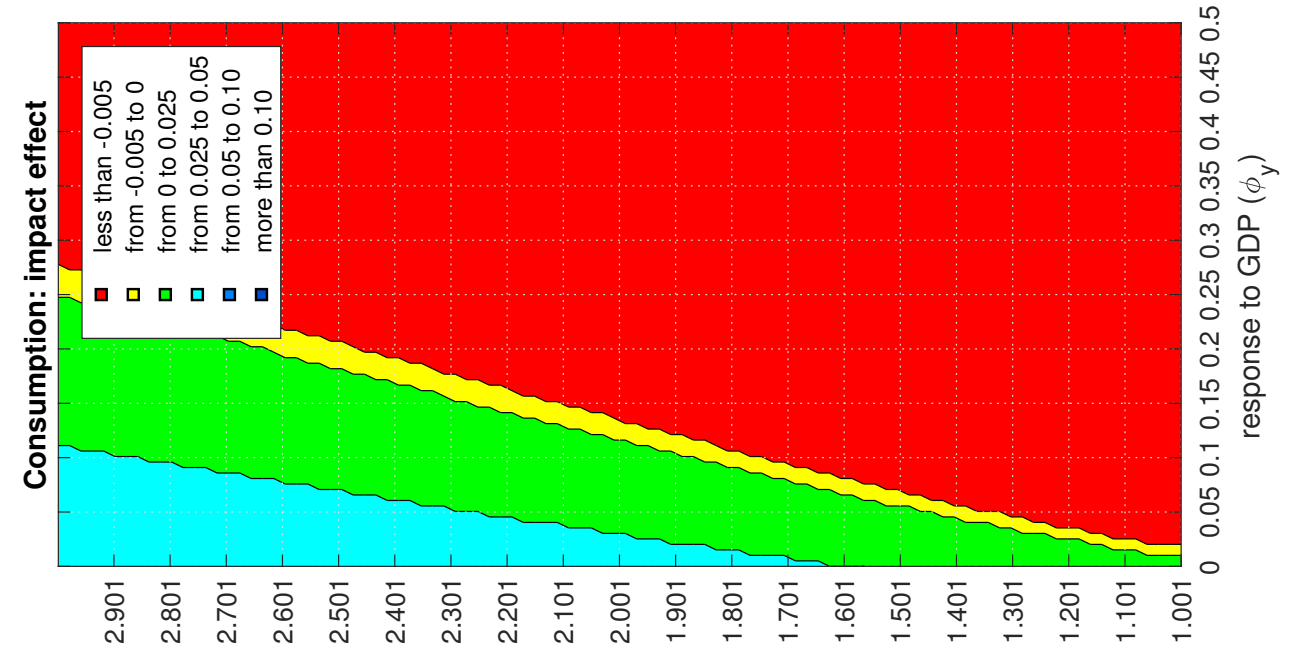

$\left({ }^{\Perp} \phi\right)$ uo!̣e|נu! ol əsuodsəג 